\title{
LAGUNA LA TIGRA. UN SITIO DE CAZADORES-RECOLECTORES DEL HOLOCENO TARDÍO EN EL ÁREA DE VALLES TRANSVERSALES (PROVINCIA DE LA PAMPA)
}

\section{LAGUNA LA TIGRA. A LATE HOLOCENE HUNTER-GATHERER SITE IN THE VALLES TRANSVERSALES AREA (LA PAMPA PROVINCE)}

\author{
Florencia Natalin Paez ${ }^{1}$
}

1IDECU-CONICET, Museo Etnográfico “Juan Bautista Ambrosetti”, Facultad de Filosofía y Letras, Universidad de Buenos Aires, Argentina. Email: fnatapaez@gmail.com

Presentado: $23 / 06 / 2020$

Aceptado: $10 / 11 / 2020$

\section{Resumen}

Se presentan los resultados obtenidos a partir del análisis de diferentes evidencias arqueológicas recuperadas en el sitio Laguna La Tigra. Este sitio se ubica en la cabecera del valle de Hucal, a ca. $30 \mathrm{~km}$ al sur-sudoeste de la localidad de Guatraché, departamento de Hucal, provincia de La Pampa. Se trata de una laguna con alto contenido de sulfato, rodeada por una barranca en constante erosión debido a los cambios en el nivel de agua. La Tigra es parte de un conjunto de sitios arqueológicos ubicados en el área de Valles Transversales, con escasos antecedentes y de gran potencial para la investigación arqueológica. El material arqueológico fue recuperado superficialmente en seis sectores: cuatro playones localizados en la costa norte, un sector denominado La Isla y otro Playa. En base a la datación de restos humanos allí recuperados, se ubica cronológicamente en el Holoceno Tardío final, al igual que otros sitios identificados dentro del área. Se hallaron también, artefactos líticos, fragmentos cerámicos, material faunístico, una cuenta vitrea y un fragmento de olla de fundición, cuyos análisis son el objetivo principal de esta publicación. Las diferentes evidencias culturales recuperadas, sumadas al fechado obtenido, permiten interpretar este ambiente lagunar, como un espacio con diversas historias ocupacionales desde por lo menos ca. 600 años AP hasta tiempos históricos. Los resultados serán discutidos e integrados en relación a la información disponible para la Región.

Palabras claves: cazadores-recolectores, ambientes lagunares, Holoceno tardí, valles transversales.

\begin{abstract}
The data obtained from the analysis of different archaeological evidences recovered at Laguna La Tigra site are presented. This site is located at the Hucal valley, ca. $30 \mathrm{~km}$ southsouthwest of the Guatraché town, Hucal department, La Pampa province. It is a lagoon with a high sulfate content, surrounded by a gully submitted to constant erosion due to changes in the water level. La Tigra is part of a set of archaeological sites located in Valles Transversales area, with great potential for archaeological research. The archaeological material was superficially
\end{abstract}


recovered in six sectors: four beaches located on the north coast, La Isla and Playa sectors. Based on the dating of human remains, it corresponds to the final Late Holocene, like other sites identified within the area. Lithic artifacts, sherds, faunal remains, a vitreous bead and a foundry pot fragment were also found and analyzed in this publication. The different cultural evidences recovered, added to the dating obtained, allow us to interpret this lagoon environment as a space with different occupational histories from at least ca. 600 years BP to historical times. The results will be discussed and integrated in relation to the information available for the Region.

Key words: hunter-gatherers, lagoon environments, late Holocene, transverse valleys.

\section{Introducción}

Este trabajo se enmarca dentro de un Proyecto de Arqueología Regional, cuyo objetivo general es aportar a la comprensión de la dinámica poblacional de los grupos cazadores-recolectores prehispánicos que transitaron el Corredor Bioceánico Norpatagónico en torno a los paralelos $36^{\circ}$ a $39^{\circ}$ LS (Berón 2004, 2007a, 2007b, 2013). La subregión de estudio comprende diferentes microrregiones del centro-sur de la provincia, entre ellas la Cuenca Media del río Colorado, la Cuenca del río ChadileuvúCuracó, las Sierras Pampeanas Meridionales, los Valles Transversales y Bajos sin Salida (Figura 1). Los datos bioantropológicos junto a los materiales líticos, cerámicos, malacológicos, adornos metálicos, cuentas minerales y elementos extra-regionales recuperados en diferentes sitios arqueológicos de estos sectores, dan cuenta de que la franja comprendida entre los 36 a $39^{\circ}$ LS, habría funcionado durante los últimos dos milenios como una zona de intensa dinámica entre poblaciones de puntos distantes como la pampa bonaerense -incluida la costa atlántica- hasta la Araucanía chilena (Berón 2018; Berón et al. 2017; Berón et al. 2020; Mazzanti 2007; Mera y Munita 2008; Munita et al. 2015).

Desde el año 2004, el grupo de Arqueología de Pampa Occidental (APO) investiga en forma sistemática la microrregión de Valles Transversales. A partir de las tendencias observadas en los primeros trabajos (Berón et al. 2002-2004; Berón et al. 2007), se planteó la posibilidad de distinguir contextos culturales correspondientes a diferentes grupos sociales, en comparación con los estudiados en el sudoeste de la provincia de La Pampa (Berón 2004, 2007b). Berón (2004) ha propuesto que los valles transversales habrían funcionado como corredores de comunicación social entre las poblaciones asentadas en ambas subregiones de la Región Pampeana (subregión Pampa Oriental y Pampa Occidental). También habrían constituido rasgos fisiográficos importantes en la delimitación de territorios (Berón et al. 2002-2004; Berón et al. 2015). 


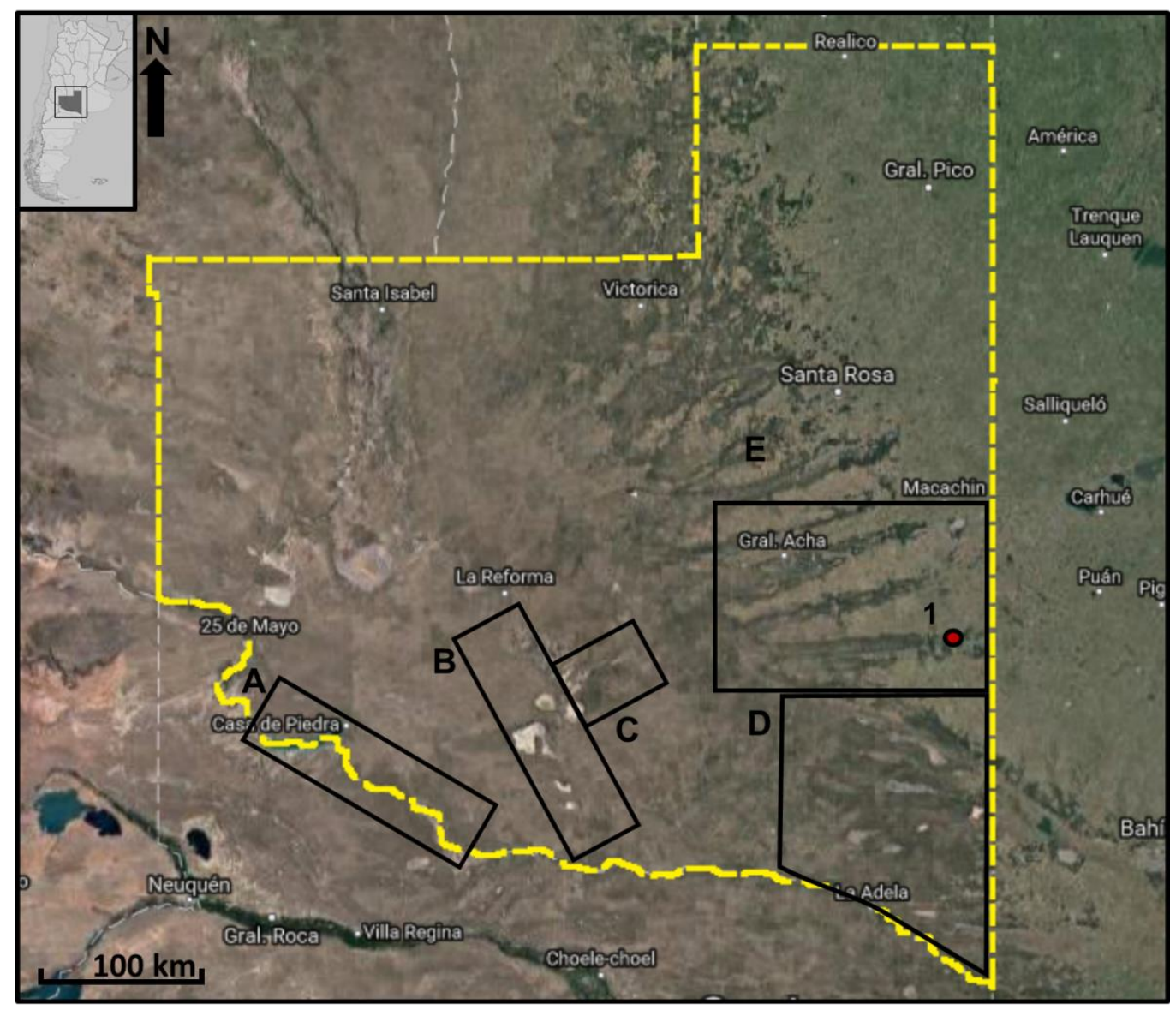

Figura 1. Microrregiones de estudio mencionadas en el texto: a) Cuenca Media del río Colorado; b) Cuenca del río Chadileuvú-Curacó; c) Sierras Pampeanas Meridionales; d) Bajos sin Salida; e) Valles Transversales. 1. Sitio arqueológico Laguna La Tigra.

Hasta el momento, se han detectado sitios arqueológicos en relación a dos valles: Valle Argentino y Valle de Hucal (Figura 2). En el caso del primero, se han identificado los sitios El Carancho 1 y 2, Médanos de Costilla, Médanos de Phagouapé, Salinas Grandes, Médanos de Alduncín, La Cascada, Bajo de Atreucó y Localidad Arqueológica Laguna Chillhué (sitio 1, 2 y 3). Por otra parte, en el valle de Hucal se han identificado los sitios Laguna La Tigra, Laguna de Guatraché y siete sitios agrupados en la Localidad Arqueológica San Sixto: El Carmel, Médano de San Sixto, Bajo de Marcelino, Luis Otero, La Tranquera, Bajada La Minnesota y Médano La Minnesota (Berón 1996-1998; Berón et al. 2002-2004; Berón et al. 2015). En este trabajo se presentan los resultados del análisis realizado sobre la totalidad de evidencias culturales recolectadas en Laguna La Tigra (Valle de Hucal). El objetivo particular del trabajo es realizar una caracterización de los diferentes conjuntos materiales y discutir las posibles actividades desarrolladas en el sitio. Posteriormente, los resultados se integran a la información disponible para otras microrregiones, con el fin de observar las particularidades del conjunto artefactual de La Tigra en un contexto espacial más amplio. 


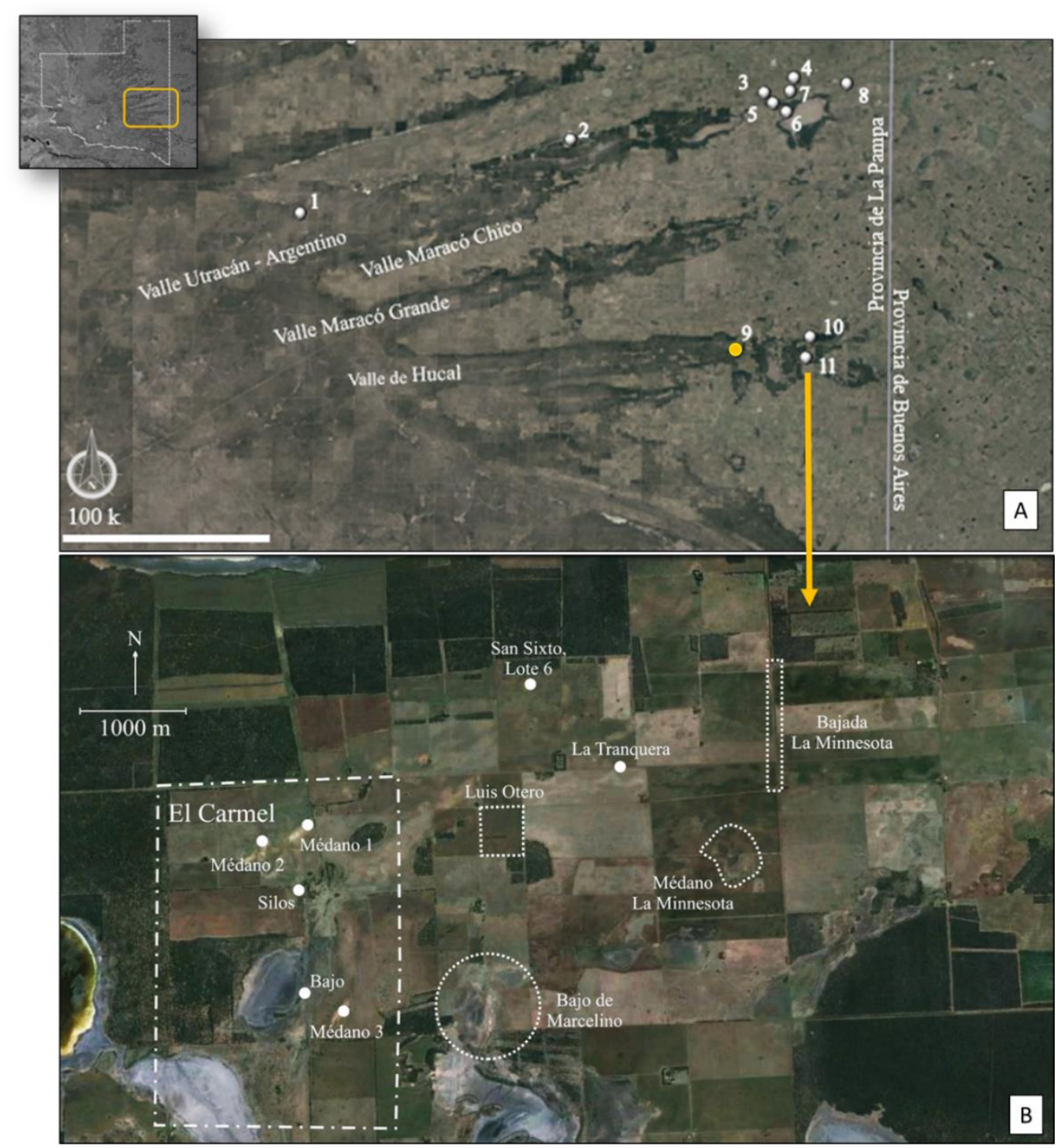

Figura 2. A. Ubicación de los sitios arqueológicos en relación a los valles mencionados en el texto. Valle Argentino: 1- El Carancho, 2- Localidad Arqueológica Laguna de Chillhué, 3Médanos de Costilla, 4- Médanos de Phaguapé, 5- Salinas Grandes, 6- Médanos de Alduncín, 7La Cascada, 8- Bajo de Atreucó. Valle de Hucal: 9- Laguna La Tigra, 10- Laguna Guatraché, 11Localidad Arqueológica San Sixto. B. Sector Ampliado de la Localidad arqueológica San Sixto.

\section{Descripción general del área de estudio}

\section{Microrregión de Valles Transversales}

La característica geomorfológica que distingue al área de estudio es el Sistema de Valles Transversales de rumbo OSO-ENE y marcado paralelismo (Terraza et al. 1981). Estos valles están dispuestos con una distribución en forma de abanico desde el sector central hacia el oriente de la provincia (Calmels 1996; Calmels y Casadío 2004). Tienen una longitud aproximada entre 100 y $150 \mathrm{~km}$ y su ancho varía entre 5 y $15 \mathrm{~km}$; el relieve relativo entre la planicie y los sectores más bajos de los valles varía entre 50 y $100 \mathrm{~m}$. La red de drenaje está compuesta por escasos cursos efímeros de diseño subparalelo, cuyos caudales esporádicos son producto de 
precipitaciones excepcionales, características del clima semiárido que domina la región. Estos cursos han formado cañadones, cárcavas o zanjones por donde escurre el agua hacia los sectores más deprimidos de los valles, los cuales albergan cordones medanosos, lagunas, salinas o salitrales, permanentes y temporarios (Terraza et al. 1981).

Es un ecosistema de transición entre las subregiones Pampa Oriental y Pampa Occidental. En el sector noreste el clima es subhúmedo seco con precipitaciones anuales que oscilan entre 450-600 mm, mientras que, en el sudoeste, el clima es semiárido (INTA 1980). Los valles presentan una amplia gama de recursos bióticos (Medus et al. 1982), con predominio del bosque abierto de caldén (Prosopis caldenia), los pastizales psamófilos, las gramíneas intermedias y los matorrales halófilos donde destaca un estrato de matas y, en algunos casos, un estrato de gramíneas y herbáceas (INTA 1980). En cuanto a la fauna, el Dominio Pampásico se extiende por el este del departamento Atreucó y noreste de Guatraché, en tanto que en el resto del área está representado el Dominio Central o Subandino (Ringuelet 1961). El área ofrece gran variedad de especies de carnívoros, herbívoros, roedores, edentados, reptiles, aves y batracios (Medus et al. 1982).

Una característica importante de la microrregión, es que no se han identificado afloramientos de rocas aptas para la confección de artefactos líticos. Debido a ello, todas las materias primas recuperadas en el registro arqueológico son de procedencia alóctona. Esto implica que los grupos cazadores-recolectores debieron implementar estrategias específicas para obtenerlas, o bien que estos recursos estuvieron incluidos en los circuitos de movilidad de dichas poblaciones. Los contextos artefactuales de esta área registran características particulares que los diferencian respecto de otras zonas de la Pampa Occidental (Berón et al. 2015).

\section{Sitio arqueológico Laguna La Tigra}

El sitio se ubica en el departamento de Hucal, sector centro-este de la provincia $\left(37^{\circ} 45^{\prime} 32.40^{\prime \prime} S\right.$ y $63^{\circ} 50^{\prime} 47.70^{\prime \prime} \mathrm{O}$; Figura 1 y 2 ). Se trata de una laguna efímera evaporítica de matriz limo-arenosa rodeada por una barranca en constante erosión debido al cambio en el nivel de agua. En su entorno se observa la presencia de bosque xerófilo con asociaciones de caldenes (Prosopis caldenia) y algarrobos (Prosopis sp.), acompañados por molles (Schinus molle), sombras de toros (Jodina rhombifolia), zampa (A fripiex sp.), matacebo (Monitea aphyila), papa de monte (Prosopanche americana), chañar (Geoffroea decoriicans), piquillín (condalia microphylla), chilladora (Ghuquiraga erinacea), salicornia (Salicornia sp.), entre otros. Actualmente, la laguna es explotada por la empresa Pagrun S.A.M.I.C.A., que durante el invierno extrae sulfato de sodio. Esta actividad genera un gran impacto sobre el sitio arqueológico por la remoción de grandes volúmenes de sedimentos y el constante ingreso de camiones que alteran la dinámica sedimentaria del paisaje. El agua de la Laguna es altamente salina, no apta para el consumo humano (Rodier 2009). Presenta $33,5 \mathrm{mS} / \mathrm{cm}$ de conductividad (o de 
sales disueltas), es decir $17 \mathrm{mS} / \mathrm{cm}$ menos que el agua de mar. Sin embargo, agrupa en su entorno, todo un ecosistema adaptado a estas condiciones, incluyendo diferentes mamíferos, aves y recursos vegetales como la papa de monte.

Fue visitada por primera vez en el año 2008 a partir de la información brindada por un coleccionista local, el Sr. Hugo Vargas quien cedió a los investigadores restos humanos (fragmento de maxilar y tibia), hallados en el perfil de la barranca norte. El equipo prospectó el sector señalado por Vargas, hallando un fragmento proximal de costilla y una diáfisis de fémur, también humanos. Se obtuvo un fechado radiocarbónico mediante la técnica AMS a partir de un primer molar superior, cuyo resultado es $590 \pm 20$ años AP (UGAMS 21347; Berón et al. 2015).

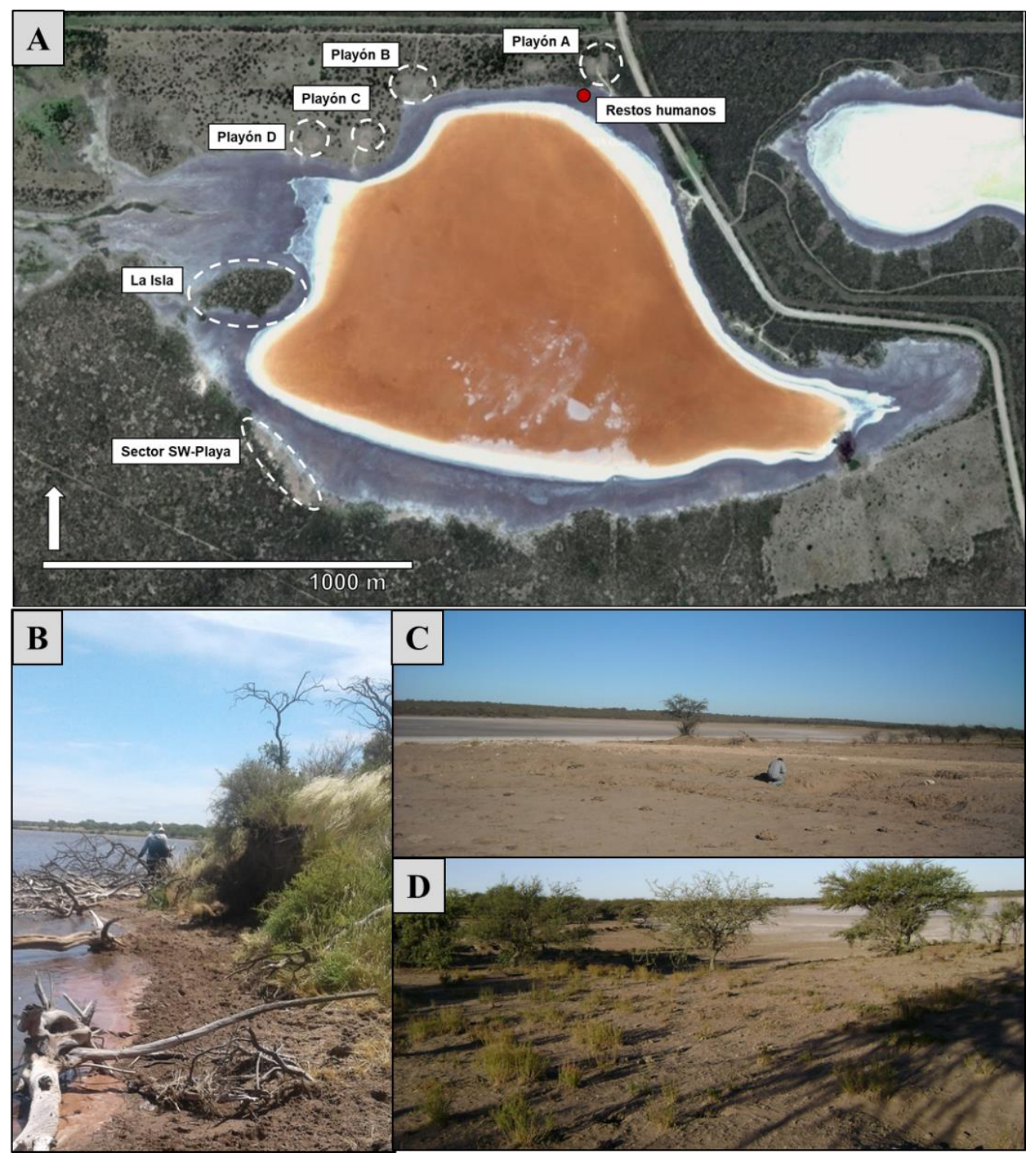

Figura 3. Laguna La Tigra: A- Sectores prospectados: Playón a, b, c, d, La Isla, Playa y ubicación donde fueron recuperados los restos humanos; B- Barranca Norte; C- Detalle del Playón b y D- Detalle del Playón c. 
En esa oportunidad y durante las campañas realizadas en los años 2009 y 2017, se realizaron exploraciones pedestres a lo largo de la margen norte y suroeste de la laguna. Durante la recolección de materiales superficiales fueron priorizados seis sectores, por presentar condiciones óptimas de visibilidad: cuatro playones actualmente desmontados denominados en sentido este-oeste como " $\mathrm{A}$ ", "B", “C" y "D", un sector denominado "La Isla" y otro "Playa" (Berón et al. 2015; Carrera Aizpitarte 2014; Figura 3). Se realizaron tres sondeos de $1 \mathrm{~m}^{2}$ en lugares que no presentaban perturbaciones recientes. Sobre la barranca norte del playón "B", el sondeo 1 alcanzó una profundidad de 0,90 m. En los primeros 0,10 m se recuperaron escasas microlascas líticas. El sondeo 2 se realizó en la barranca norte del playón "C" y el sondeo 3 en "La Isla". Estos últimos alcanzaron una profundidad de $0,60 \mathrm{~m}$, sin resultados positivos. El registro arqueológico cultural hallado en superficie, consta de fragmentos cerámicos, artefactos líticos, material zooarqueológico, una cuenta vítrea y un fragmento de olla de hierro.

\section{Consideraciones Metodológicas}

El material analizado en este trabajo corresponde al total de evidencias superficiales recolectadas durante las prospecciones. Para el análisis, los materiales fueron considerados como un solo cuerpo de datos debido a que la diferenciación entre unidades de recolección (Playones A, B, C, D, La Isla y Playa) responde a cuestiones de visibilidad del registro superficial y no, a una composición diferencial de la muestra a nivel intra sitio.

El conjunto lítico fue clasificado en tres categorías: núcleos, desechos y artefactos formatizados (sensu Aschero 1975). En todos los casos se registraron las dimensiones, forma base, tipo de materia prima y reserva de corteza (Aschero 1975, 1983; Aschero y Hocsman 2004). Además, se relevaron atributos específicos para cada una de las categorías artefactuales mencionadas. Para el análisis de los núcleos se siguieron los lineamientos generales propuestos por Paulides (2006). Se evaluó el tipo de núcleo, la cantidad mínima de extracciones, el tipo de plataforma y su estado. En los desechos se consideró el tipo de lasca, tipo de bulbo y talón, presencia de rastros complementarios del talón, labio, estrías, curvatura y tipo de fractura (Aschero 1975, 1983; Bellelli et al. 1985-1987). También se incorporaron categorías específicas de productos bipolares, como machacados, talones astillados, fracturas escalonadas, bulbos de fuerza en ambos extremos o la combinación de un positivo de bulbo en un extremo y un negativo en el otro, entre otras características morfológicas (Bonomo 2004; Curtoni 1996; Flegenheimer et al. 1995; Nami 2000). Para artefactos formatizados se relevaron una serie de atributos como estado; calidad de la materia prima; grupo tipológico; dimensiones; forma base; cantidad de filos, serie técnica, entre otros (Aschero 1975, 1983; Aschero y Hocsman 2004). 
El material cerámico fue analizado macroscópicamente y con bajos aumentos (lupa binocular 10x). Cada tiesto fue medido, registrando su tamaño y el espesor de las paredes, además de indicar la sección correspondiente (cuerpo, borde o base). Para el análisis cualitativo se siguió la metodología clasificatoria propuesta por Berón (2004) en su Tesis Doctoral. A partir del análisis de los tiestos cerámicos de la Localidad arqueológica Tapera Moreira y su experiencia previa con los del área de Casa de Piedra, Berón elabora esta propuesta basándose en la observación y sistematización de determinados atributos tecnológicos y tipológicos (atmósfera de cocción, tamaño de las inclusiones, tratamiento de la superficie y técnicas de decoración). Las unidades taxonómicas aisladas a partir de esos atributos compartidos, fueron denominadas grupos cerámicos, definiendo un total de 12 grupos no-decorados y cuatro grupos decorados (Berón 2004).

Con el fin de evaluar el grado de fragmentación del conjunto se tomó y modifico el modelo propuesto por Borges Vaz et al. (2015), donde se establecen categorías de tamaños expresadas en milímetros para el largo y ancho de los tiestos. Para los fragmentos recuperados en La Tigra, la longitud se discriminó según los rangos muy corto $(0-20,00)$, corto $(20,01-40,00)$, mediano $(40,01-60,00)$, largo $(60,01-80,00)$; mientras que el ancho se dividió en muy angosto (0-20,00), angosto (20,01-40,00), mediano $(40,01-60,00)$, ancho $(60,01-80,00)$. Para estimar el número mínimo de vasijas (NMV) se siguieron y adaptaron los criterios metodológicos propuestos por Feely y Ratto (2013). Para esto se sumaron los valores obtenidos para A: cantidad de vasijas identificadas en función de los bordes + B: cantidad de grupos cerámicos diferenciados en el conjunto; ya que en el caso de La Tigra, no hay otras variables distintivas entre los tiestos.

Los restos faunísticos fueron identificados anatómica y taxonómicamente a partir del análisis comparativo con muestras de referencia actuales. Lo mismos fueron posteriormente cuantificados empleando las medidas y criterios zooarqueológicos tradicionales (Mengoni Goñalons 1999, 2006-2010). Para la totalidad de los taxones determinados se obtuvieron las medidas de: abundancia taxonómica y anatómica, número de especímenes óseos identificados por taxón (NISP) y número mínimo de individuos (MNI) (Grayson 1984; Klein y Cruz-Uribe 1984; entre otros). Con el objetivo de evaluar la integridad de la muestra, se consideraron las siguientes variables tafonómicas: meteorización (e.g. líneas y grietas de desecación, exfoliación de láminas corticales y astillamiento), la disolución y la depositación química (e.g. carbonato de calcio y óxido de manganeso), presencia de marcas de raíces, marcas de roedores, marcas de carnívoros, pisoteo, tipo de fractura y abrasión sedimentaria (Behrensmeyer 1978; Binford 1981; Grayson 1984; Haynes 1980; Johnson 1985; Lyman 1994; Olsen y Shipman 1988; Shipman 1981). Con el objetivo de identificar indicadores de procesamiento del conjunto óseo, se consideraron las siguientes variables: alteración térmica (Benett 1999; David 1990), tipo de fractura (Johnson 1985) y huellas de corte (Binford 1981; Shipman 1981). 
La cuenta vítrea fue catalogada siguiendo el sistema de clasificación propuesto por Kidd y Kidd (1983) y Kidd y Kenneth (2006). Para la determinación del color se utilizó el Atlas de Colores de Küppers (2002). Las dimensiones de la cuenta fueron tomadas utilizando un calibre digital. La cuenta fue expuesta a la luz artificial y natural para evaluar el grado de transparencia que presentaba el vidrio (Flensborg y Wagner 2015). El fragmento ferroso fue medido utilizando calibre digital. Ambos materiales fueron pesados utilizando una balanza de precisión. El registro fotográfico se realizó mediante el empleo de un microscopio digital Dino-Lite con una magnificación de 40x.

\section{Resultados}

\section{Análisis Lítico}

Fueron analizados un total de 3083 artefactos líticos. El conjunto está conformado principalmente por desechos de talla, los cuales constituyen el 92,21 $\%$ del total $(\mathrm{n}=2843)$. Los artefactos formatizados suman el 6,81 \% ( $\mathrm{n}=210)$, mientras que los núcleos el $0,97 \%(\mathrm{n}=30)$. La materia prima más representada entre los artefactos recuperados en La Tigra, corresponde a las rocas silíceas de buena calidad para la talla. En orden de importancia, el grupo de las sílices presenta un porcentaje de 30,98 \% ( $\mathrm{n}=955)$. Bajo esta denominación se han agrupado una gran variabilidad de materias primas silíceas, donde no se ha podido establecer su tipo específico (Berón 2004, 2006). Siguen en orden de importancia el chert -caliza silicificada- con un valor de $24,49 \%$ ( $\mathrm{n}=755$ ), cuarcitas $(17,16 \%, n=529)$, y calcedonia 14,14 \% ( $=436$; Tabla 1, Figura 4). Es importante mencionar que se recuperó una lasca entera primaria de tamaño pequeño de obsidiana. Fue analizada mediante la técnica de Fluorescencia de Rayos X (XRF) en el MURR (Missouri University Research Reactor). El resultado del análisis indica su procedencia de la subfuente Arroyo Paramillos, ubicadas en la provincia de Mendoza (ver Figura 2 en Berón et al. 2018).

Los desechos fueron divididos en cuatro categorías según se trate de lascas enteras (LENT), lascas fracturadas con talón (LFCT), lascas fracturadas sin talón (LFST) o desechos indiferenciados (INDI) (Bellelli et al. 1985-1987). Esta última categoría incluye a todas aquellas piezas en las cuales no ha sido posible distinguir los atributos que hubieran permitido clasificarlas como lascas. El tipo de lasca predominante entre todas las materias primas representadas, son las lascas fracturadas (LFCT + LFST). Este conjunto, representa el 56,51 \% ( $\mathrm{n}=1607)$, del total de los desechos analizados. Las LENT suman el 35,21 \% (n = 1001) y los INDI un 8,16 \% del total. Este porcentaje incluye 37 chunks $^{1}(1,30 \%)$ y $195(6,86 \%)$ no diferenciados (Tabla 1). 


\begin{tabular}{|c|c|c|c|c|c|c|c|c|c|c|}
\hline \multirow{2}{*}{$\begin{array}{l}\text { MATERIA } \\
\text { PRIMA }\end{array}$} & \multicolumn{6}{|c|}{ DESECHOS } & \multirow{2}{*}{ INSTRUMENTOS } & \multirow[t]{2}{*}{ NÚCLEOS } & \multirow[t]{2}{*}{ TOTAL } & \multirow[t]{2}{*}{$\%$} \\
\hline & LENT & LFCT & LFST & CHUNK & NO DIF & TOTAL & & & & \\
\hline Arenisca & - & - & 2 & - & 1 & 3 & 2 & - & 5 & 0,16 \\
\hline Basalto & 47 & 34 & 36 & - & 3 & 120 & 1 & - & 121 & 3,92 \\
\hline Calcedonia & 167 & 90 & 129 & 4 & 17 & 407 & 27 & 2 & 436 & 14,14 \\
\hline Chert & 248 & 146 & 228 & 1 & 52 & 675 & 57 & 23 & 755 & 24,49 \\
\hline Cuarcita & 197 & 130 & 185 & 7 & 7 & 526 & 2 & 1 & 529 & 17,16 \\
\hline Cuarzo & 32 & 28 & 60 & 6 & 15 & 141 & 1 & - & 142 & 4,61 \\
\hline Esquisto & - & - & - & - & 2 & 2 & - & - & 2 & 0,06 \\
\hline Gabro & 3 & - & 2 & - & - & 5 & - & - & 5 & 0,16 \\
\hline Granito & - & 1 & - & - & 2 & 3 & 1 & - & 4 & 0,13 \\
\hline Indet. & 15 & 7 & 22 & - & 63 & 110 & 1 & - & 111 & 3,60 \\
\hline $\begin{array}{l}\text { Madera } \\
\text { Silicificada }\end{array}$ & 2 & - & 1 & - & - & 3 & - & - & 3 & 0,10 \\
\hline Pórfido & 2 & 2 & 2 & - & - & 6 & - & - & 6 & 0,19 \\
\hline Sílice & 287 & 202 & 298 & 19 & 31 & 837 & 115 & 3 & 955 & 30,98 \\
\hline $\begin{array}{l}\text { Sílice en } \\
\text { plaqueta }\end{array}$ & - & 1 & 1 & - & 2 & 4 & 3 & - & 7 & 0,23 \\
\hline Riolita & - & - & - & - & - & - & - & 1 & 1 & 0,03 \\
\hline Obsidiana & 1 & - & - & - & - & 1 & - & - & 1 & 0,03 \\
\hline SUBTOTALES & 1001 & 641 & 966 & 37 & 195 & 2843 & 210 & 30 & 3083 & 100 \\
\hline
\end{tabular}

Tabla 1. Estructura del conjunto lítico de Laguna La Tigra. Referencias: LENT: Lasca entera; LFST: Lasca fracturada sin talón; LFCT: Lasca fracturada con talón; NO DIF: No diferenciado; INDET: Indeterminado

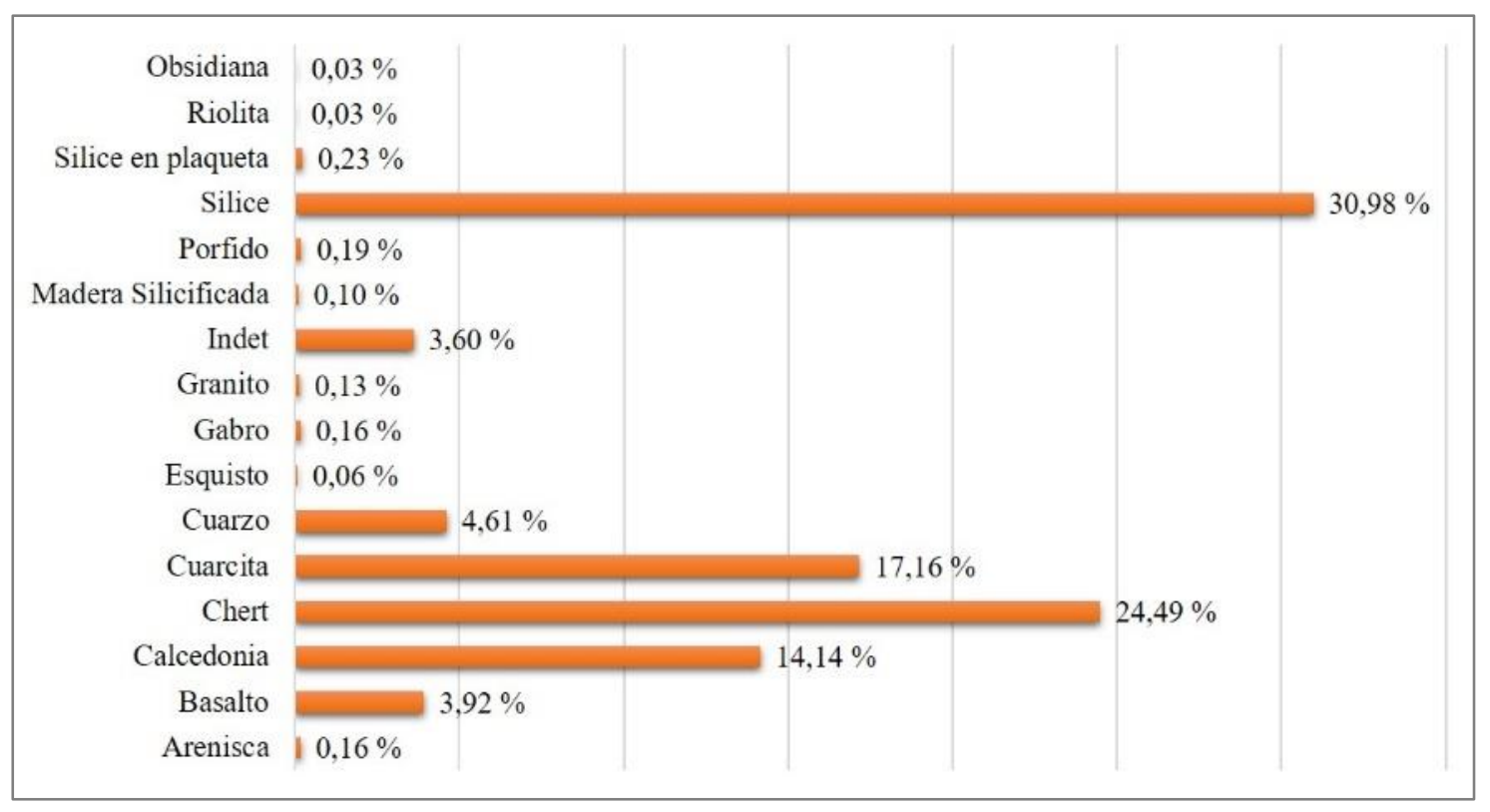

Figura 4. Representación de las materias primas identificadas en La Tigra

Si consideramos el tipo de lasca, observamos que el 69,43\% corresponde a angulares (n =695). Otras lascas de alta representación en el conjunto son las planas ( $\mathrm{n}=106,10,58 \%$ ), las de arista $(n=62,6,19 \%)$ y los desechos bipolares $(n=60,5,99 \%)$. Con respecto a los desechos bipolares, vale aclarar que se han agrupado en esta categoría a los desechos que presentaban atributos claros de bipolaridad. Es probable que muchos de los desechos 
clasificados como INDI (pequeñas astillas, por ejemplo) correspondan a subproductos de la talla bipolar pero al carecer de atributos morfológicos claros que permitan identificarlo dentro de esta categoría se ha decidido mantenerlos en la categoría de Indiferenciados (Curtoni 1996; Velardez 2005, 2018). Los desechos bipolares corresponden principalmente a rocas silíceas indeterminadas, chert y calcedonia. El índice de presencia de corteza registrado entre el total de los desechos es muy bajo. Sólo el 7,90 \% $(n=225)$ presenta restos de corteza en su cara dorsal, principalmente entre desechos de silice $(n=70)$, chert $(n=57)$, calcedonia $(n=48)$, cuarcita $(n=31)$ y basalto $(n=19)$. Para evaluar la relación entre tamaño y módulo de longitud-anchura solo fueron consideradas las piezas enteras $(\mathrm{n}=1001)$. Las lascas "pequeñas" ( $n=578)$ seguidas por las "muy pequeñas" $(n=335)$ son las que predominan en el conjunto. Por otra parte, los módulos de longitud-anchura más frecuentes son el "mediano normal" $(\mathrm{n}=480)$ y el "corto ancho" $(\mathrm{n}=224)$.

En relación a la clase tipológica de Artefactos Formatizados, la Tabla 2 muestra la distribución de los 14 (catorce) grupos tipológicos representados. Se ha incluido en ella, el detalle de los distintos grupos y su distribución por tipo de materia prima. El mayor porcentaje corresponde al grupo de los raspadores $(35,71 \%, \mathrm{n}=75)$, siguiéndole, en orden de importancia, las puntas de proyectil $(31,90 \%, \mathrm{n}=67)$ y los fragmentos de artefactos no diferenciados $(16,19 \%, \mathrm{n}=34$, Tabla 2). El 13,39\% ( $\mathrm{n}=28)$ de los instrumentos fue clasificado como compuestos, dado que presentan dos o más filos (o puntas) formatizadas, pertenecientes a grupos tipológicos diferentes (Aschero 1975, 1983). Los grupos tipológicos que suelen aparecer combinados suelen ser puntas destacadas entre muescas, raspadores y raederas con filos de formatización sumaria, raspadores con Spur, entre otros.

\begin{tabular}{|c|c|c|c|c|c|c|c|c|c|c|c|c|c|c|c|c|c|c|c|c|c|c|}
\hline $\begin{array}{c}\text { Grupo } \\
\text { Tipológico }\end{array}$ & AR & $\%$ & BAS & $\%$ & CAL & $\%$ & CHS & $\%$ & CUA & $\%$ & CZO & $\%$ & GRA & $\%$ & Indet. & $\%$ & SIL & $\%$ & $\begin{array}{l}\text { SIL } \\
\text { PLQ }\end{array}$ & $\%$ & Total & $\%$ \\
\hline Chopper & 1 & 50,0 & - & - & - & - & - & - & - & - & - & - & - & - & - & - & - & - & - & - & 1 & 0,48 \\
\hline Cuchillo & $\cdot$ & - & 1 & 100 & - & - & 1 & 1,75 & - & - & - & - & - & - & - & - & 2 & 1,74 & - & - & 4 & 1,90 \\
\hline $\begin{array}{c}\text { Denticulad } \\
0\end{array}$ & $\cdot$ & - & - & - & - & - & - & - & - & - & 1 & 100 & - & - & - & - & 1 & 0,87 & - & - & 2 & 0,95 \\
\hline $\begin{array}{l}\text { Fr. ND de } \\
\text { Artef. } \\
\text { Form. }\end{array}$ & - & - & - & - & 1 & 3,70 & 9 & 15,79 & 1 & 50,00 & - & - & - & - & - & - & 23 & 20 & - & - & 34 & 16,19 \\
\hline L.R.S & - & - & - & - & 1 & 3,70 & 1 & 1,75 & - & - & - & - & - & - & - & - & 2 & 1,74 & 1 & 33,33 & 5 & 2,38 \\
\hline Muesca & - & - & - & - & - & - & 1 & 1,75 & - & - & - & - & - & - & - & - & 1 & 0,87 & - & - & 2 & 0,95 \\
\hline Perforador & - & - & - & - & - & - & - & - & - & - & - & - & - & - & - & - & 3 & 2,61 & - & - & 3 & 1,43 \\
\hline $\begin{array}{l}\text { Picado- } \\
\text { Pulido }\end{array}$ & 1 & 50,0 & - & - & - & - & - & - & - & - & - & - & 1 & 100 & - & - & - & . & - & - & 2 & 0,95 \\
\hline $\begin{array}{l}\text { Preforma } \\
\text { Raspador }\end{array}$ & - & - & - & - & - & - & 1 & 1,75 & - & - & - & - & - & - & - & - & - & - & - & - & 1 & 0,48 \\
\hline $\begin{array}{c}\text { Pta. } \\
\text { Destacada }\end{array}$ & - & - & - & - & 2 & 7,41 & - & - & - & - & - & - & - & - & - & - & 2 & 1,74 & - & - & 4 & 1,90 \\
\hline $\begin{array}{c}\text { Pta. } \\
\text { Proyectil }\end{array}$ & - & - & - & - & 7 & 25,93 & 14 & 24,56 & 1 & 50,00 & - & - & - & - & - & - & 44 & 38,3 & 1 & 33,33 & 67 & 31,90 \\
\hline Raedera & - & - & - & - & - & - & 2 & 3,51 & - & - & - & - & - & - & - & - & 3 & 2,61 & 1 & 33,33 & 6 & 2,86 \\
\hline Raspador & - & - & - & - & 15 & 55,56 & 27 & 47,37 & - & - & - & - & - & - & 1 & 100 & 32 & 27,8 & - & - & 75 & 35,71 \\
\hline $\mathrm{RBO}$ & - & - & - & - & 1 & 3,70 & 1 & 1,75 & - & - & - & - & - & - & - & - & 2 & 1,74 & - & - & 4 & 1,90 \\
\hline Subtotal & 2 & - & 1 & - & 27 & - & 57 & - & 2 & - & 1 & - & 1 & - & 1 & - & 115 & - & 3 & - & 210 & 100 \\
\hline
\end{tabular}

Tabla 2. Instrumentos de La Tigra. Referencias: Fr. ND de Artef. Form: Fragmento no diferenciado de artefacto formatizado; LRS: lasca con retoques sumarios; Pta. Destacada: punta destacada; Pta. Proyectil: punta de proyectil; ARE: arenisca; BAS: basalto; CAL: calcedonia; CHS: chert silíceo; CUA: cuarcita; CZO: cuarzo; GRA: granito; INDET: rocas indeterminadas; SIL: sílice; SIL PLQ: sílice en plaqueta. 
Entre el grupo de los raspadores, predominan los de filo frontal largo $(25 \%, \mathrm{n}=$ 19) y los de filo fronto lateral $(11,84 \%, \mathrm{n}=9)$. Generalmente, el tamaño de los raspadores es pequeño y sus módulos de longitud-anchura son mediano-normal y corto-ancho, similar a la mayoría de los raspadores recuperados en otros sitios de la subregión (Berón 2004, 2006; Berón et al. 2015; Carrera Aizpitarte 2014; Velardez 2005, 2018). Fueron seleccionadas para confeccionarlo rocas silíceas y como formas base lascas angulares espesas sin corteza (Figura 5a). El 34,21 \% $(n=26)$ de los raspadores, presenta sus filos embotados.

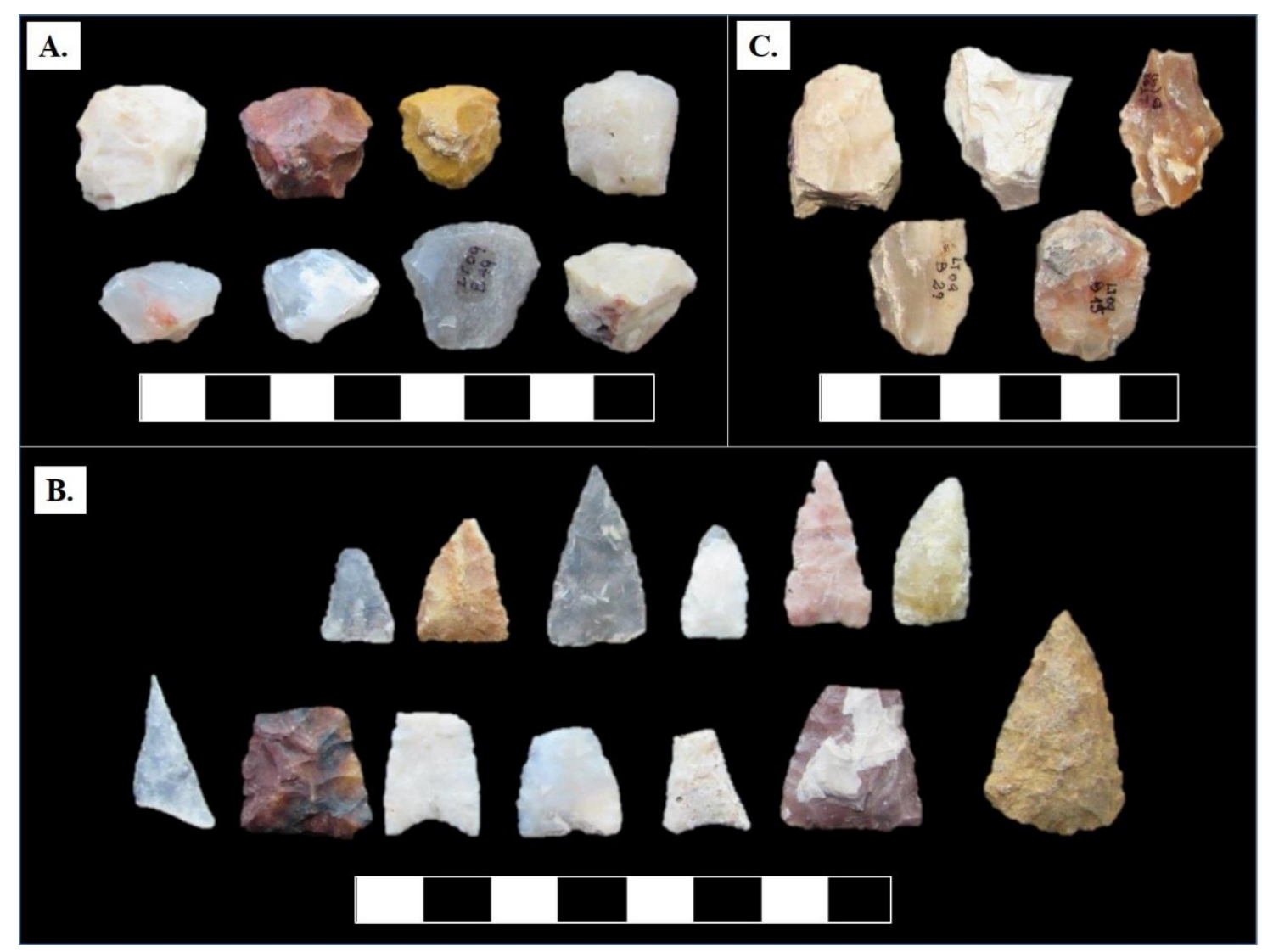

Figura 5. a) Raspadores; b) Puntas de Proyectil; c) Núcleos

Otro grupo de interés, debido a su representatividad en la muestra, son las puntas de proyectil. En todos los casos se trata de puntas triangulares apendunculadas, coincidiendo con la tendencia general observada para la Región Pampeana (Berón 1984, 2004, 2006; Carrera Aizpitarte 2014; Martínez 2008-09, 2017; Valverde y Martucci 2004; Velardez 2005). Las puntas de proyectil recuperadas en La Tigra, han sido manufacturadas en diferentes tipos de materia prima: chert, calcedonia, rocas silíceas y cuarcitas de grano fino (Figura 5b). Fueron manufacturadas a partir de retoques y microretoques bifaciales. Se caracterizan por presentar lascados irregulares, sin patrón diferencial (presentes en el 25,37 \%; $\mathrm{n}=17$ de los casos), seguidos por el retoque paralelo transversal irregular $(19,40 \% ; \mathrm{n}=13)$ y en pequeñas proporciones por retoques paralelos cortos $(14,92 \% ; n=10)$. En algunos casos $(14,92 \% ; n=10)$ los lascados no parecen seguir ningún patrón aparente (sensu Aschero 1975, 1983). El 
tamaño de las puntas, sus módulos de longitud-anchura y sus espesores son muy variables. Sin embargo, a grandes rasgos las puntas pequeñas, medianas-alargadas y poco espesas dominan la media. La forma general de las bases principalmente es rectilínea y concavilínea simple (sensu Aschero 1975, 1983).

Los núcleos suman un total de 30. Entre ellos, cinco materias primas diferentes, fueron identificadas, siendo los de chert los más representados $(76,66 \% ; n=23)$. La mayor frecuencia corresponde a núcleos bipolares $(40 \% ; n=12)$ y amorfos $(16,66 \%$; $=5$; Figura 5c). Se registran además, aunque minoritarios, núcleos globulosos, bifaciales, piramidales irregulares, discoidales y no diferenciados por fractura (Figura 6). Entre los núcleos predominan los enteros $(80 \% ; n=24)$, de tamaño pequeño. En la mayoría de los casos están agotados y/o presentan impurezas que dificultan nuevas extracciones. La presencia de corteza entre ellos es escasa, solo en dos casos y no supera el $40 \%$ del volumen total de la pieza.

Con respecto a la representación de las materias primas de los diferentes grupos tipológicos, su frecuencia entre los artefactos formatizados sigue, en líneas generales, la mencionada anteriormente para los desechos. Sin embargo, si lo analizamos en detalle, aparecen algunas diferencias (Tabla 1 y 2). Por ejemplo, los porcentajes de instrumentos confeccionados en basalto y cuarcita son muy bajos $(<1 \%)$ en relación a los desechos de estas materias primas y la representación de los núcleos es casi nula. Algo similar ocurre con la calcedonia, donde se registra la presencia de instrumentos y desechos, pero muy pocos núcleos. En el caso del granito y arenisca, puede observarse que su presencia se restringe a fragmentos de artefactos manufacturados por picado pulido. Finalmente se puede agregar que el 8,61 \% $(n=18)$ de los instrumentos, presenta rastros de corteza, principalmente entre el grupo de los Raspadores.

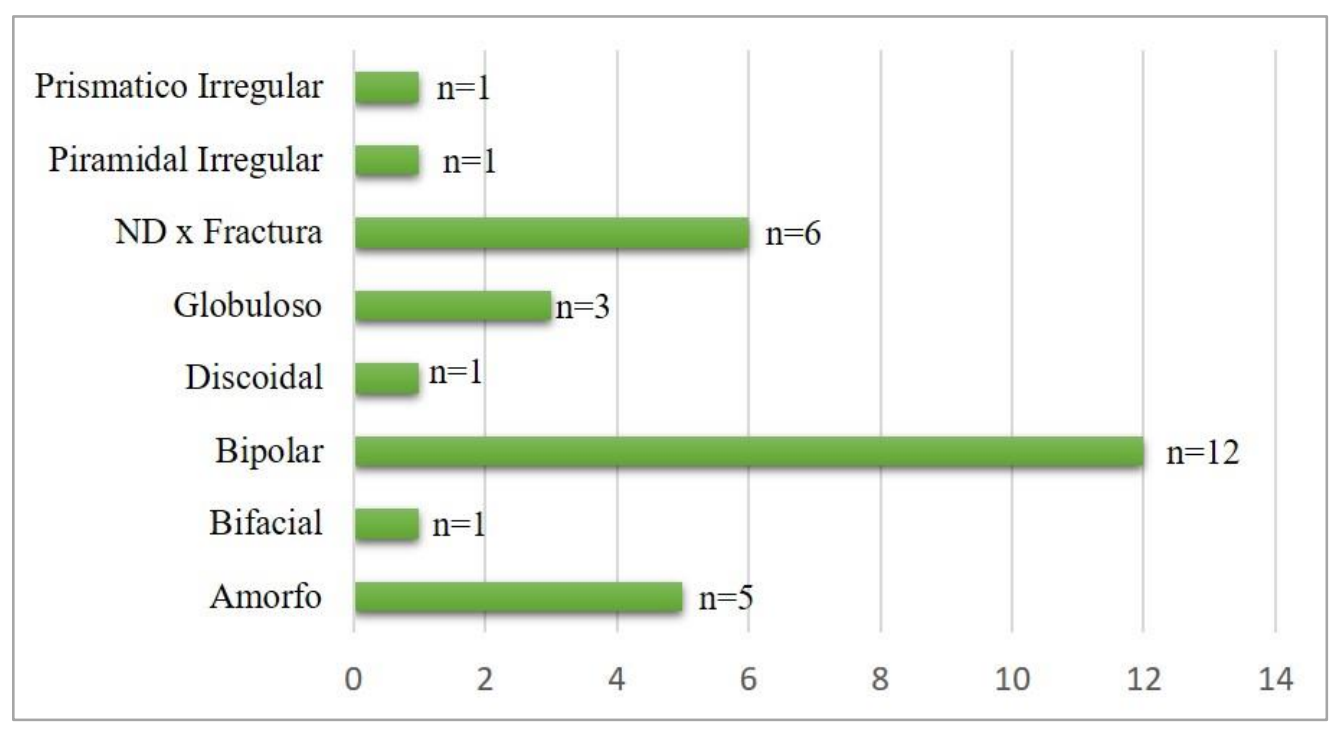

Figura 6. Frecuencia de los tipos de núcleos identificados. Referencias: ND x Fractura: No diferenciado por fractura. 
La muestra analizada se compone de 418 fragmentos de cuerpo (96 \%) y 17 de bordes (4\%). Dentro de estos últimos, 11 presentan perfiles rectos, 4 invertidos y 2 evertidos. Las medidas de los tiestos son en general similares (Tabla 3). Predominan los rangos de tamaños muy cortos $(\mathrm{n}=340 ; 78,16 \%)$ y muy angostos $(\mathrm{n}=332 ; 76,32 \%$, Tabla 3). El fragmento que destaca por su tamaño en la Tabla 3 (61,02 mm largo x 68,83 mm ancho) presenta además un agujero de suspensión y leve curvatura (Figura 7a).

\begin{tabular}{|c|c|c|c|}
\hline \multicolumn{4}{|c|}{ Largo } \\
\hline $\begin{array}{l}\text { RANGO } \\
(\mathrm{mm})\end{array}$ & DENOMINACIÓN & TOTAL & PORCENTAJE \\
\hline $60,01-80,00$ & Largo & 1 & 0,23 \\
\hline $40,01-60,00$ & Mediano & 4 & 0,92 \\
\hline $20,01-40,00$ & Corto & 90 & 20,69 \\
\hline $0-20,00$ & Muy corto & 340 & 78,16 \\
\hline & Total & 435 & 100 \\
\hline \multicolumn{4}{|c|}{ Ancho } \\
\hline $\begin{array}{l}\text { RANGO } \\
(\mathrm{mm})\end{array}$ & DENOMINACIÓN & TOTAL & PORCENTAJE \\
\hline $60,01-80,00$ & Ancho & 1 & 0,23 \\
\hline $40,01-60,00$ & Mediano & 8 & 1,84 \\
\hline $20,01-40,00$ & Angosto & 94 & 21,61 \\
\hline $0-20,00$ & Muy angosto & 332 & 76,32 \\
\hline & Total & 435 & 100 \\
\hline \multicolumn{4}{|c|}{ Espesor } \\
\hline $\begin{array}{l}\text { RANGO } \\
(\mathrm{mm})\end{array}$ & DENOMINACIÓN & TOTAL & PORCENTAJE \\
\hline $8,01-10,00$ & Muy espeso & 3 & 0,69 \\
\hline $6,01-8,00$ & Espeso & 48 & 11,03 \\
\hline $4,01-6,00$ & Mediano & 240 & 55,17 \\
\hline $2,01-4,00$ & Fino & 137 & 31,49 \\
\hline \multirow[t]{3}{*}{$0-2,00$} & Muy fino & 0 & 0,00 \\
\hline & $\mathrm{ND} \times \mathrm{F}^{*}$ & 7 & 1,61 \\
\hline & Total & 435 & 100 \\
\hline
\end{tabular}

Tabla 3. Dimensiones de los tiestos. Referencias: ND x F: No diferenciado por fractura. Cuadro tomado y adaptado de Borges Vaz et al. (2015).

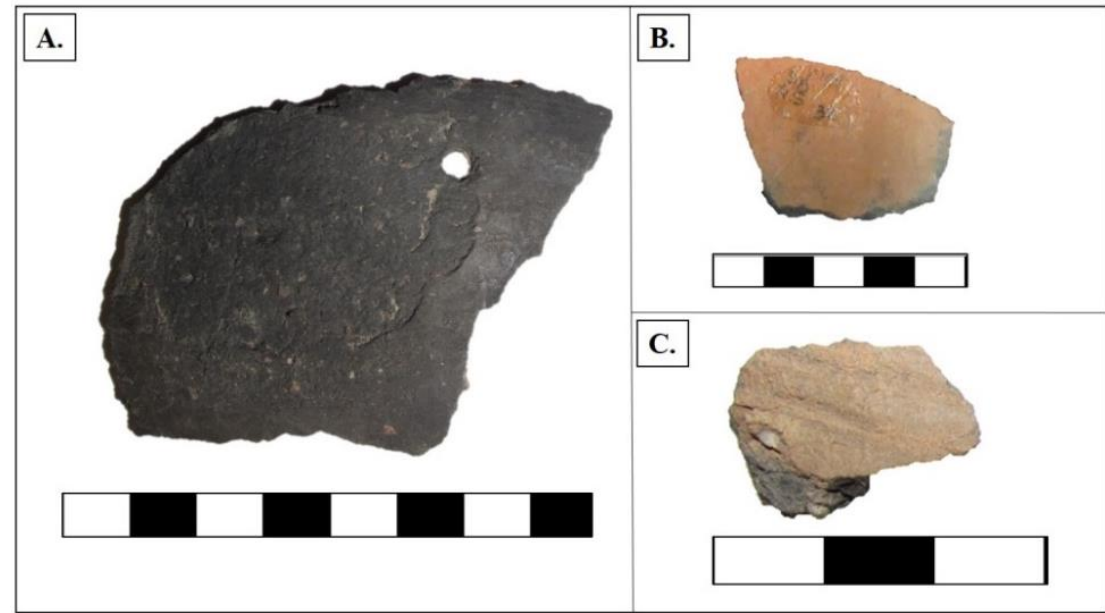

Figura 7. a) Tiesto con agujero de suspensión; b) Tiesto con engobe rojo; c) Tiesto con decoración incisa. 
En referencia al tratamiento de las superficies, predomina el alisado ( $\mathrm{n}=226 ; 51,95 \%$ ), siendo frecuentes las marcas de alisamiento. El 37,93 \% ( $n=165)$ corresponde a fragmentos toscos o poco alisados. Respecto al espesor de las paredes, se registró un mayor porcentaje de medidas comprendidas entre 4 y $6 \mathrm{~mm}$, correspondientes a la categoría mediano (Tabla 3). Una parte de la muestra $(\mathrm{n}=44 ; 10,11 \%)$ se ve afectada por la meteorización, provocando que no pueda ser identificado en estos casos el tratamiento de las superficies. Los tiestos erosionados presentan principalmente, descascarado en la superficie externa y acumulación de cristales de sales de sulfato. A partir de las observaciones macroscópicas realizadas a la pasta, se registró que cuarzo lechoso, hialino y muscovita son las inclusiones más frecuentes. Su tamaño, en general es fino. En relación con su abundancia, la categoría densa es la más frecuente. Sobre las atmosferas de cocción, la no oxidante es la más abundante $(\mathrm{n}=358 ; 82,29 \%)$. En orden decreciente se registra la oxidante incompleta $(\mathrm{n}=$ $54 ; 12,41 \%)$ y oxidante $(\mathrm{n}=23 ; 5,28 \%)$.

El 89,88 \% (n = 391) de los tiestos recuperados en La Tigra han podido ser adscriptos a alguno de los grupos cerámicos definidos por Berón (2004). Los Grupos $6(\mathrm{n}=83,19,08 \%), 2(\mathrm{n}=68,15,63 \%)$ y $9(\mathrm{n}=61,14,02 \%)$ son los más representados (Figura 8). Siguiendo a Berón (2004) los tiestos cerámicos del Grupo 6 se caracterizan por presentar pasta compacta o poco compacta. Las superficies externas se encuentran poco alisadas o toscas y el color es principalmente marrón grisáceo. Las inclusiones son de cuarzo blanco y hialino, rocas no diferenciadas, angulares; cantos rodados; de tamaño fino y abundancia densa. Su pasta es poco compacta a compacta, arenosa, porosa. Presenta cocción no oxidante. Los tiestos del Grupo 2 presentan mica entre las inclusiones de la pasta, además de cuarzo blanco y hialino. Las superficies se encuentran principalmente alisadas. El color de la superficie externa es marrón amarillento o marrón grisáceo. Se caracterizan también por una atmosfera de cocción no oxidante. Los tiestos del Grupo 9 presentan pasta compacta, granulosa, e inclusiones gruesas a muy gruesas de cuarzo blanco y hialino. Las superficies se encuentran alisadas y el color de la superficie externa varía entre el color gris, marrón grisáceo o amarillento. Cocción no oxidante.

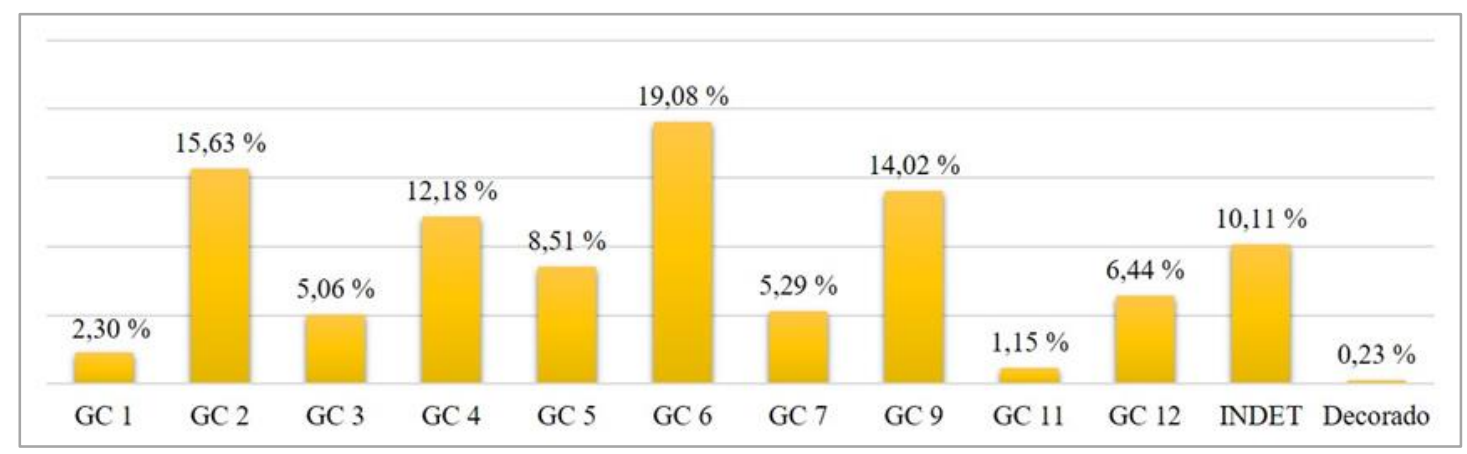

Figura 8. Frecuencia de los Grupos cerámicos identificados. 
Destacan del conjunto 5 fragmentos, clasificados como pertenecientes al Grupo 11, cuya principal característica es la presencia de engobe rojo en la superficie externa (Figura $7 \mathrm{~b}$ ). También 1 fragmento con incisiones rectas de trazo fino $(2 \mathrm{~mm})$ semiparalelas en la cara externa de la pieza, que debido a sus pequeñas dimensiones no ha podido ser asignado a ninguno de los grupos decorados por incisión, definidos para las microrregiones del Curacó y Casa de Piedra (Berón 2004, Figura 7c). Finalmente, considerando A- la cantidad de bordes presentes en la muestra $(n=17)$ sumado a Bnúmero de grupos cerámicos identificados (11) se estimó un número mínimo de vasijas (NMV) de 28 para este sitio (Feely y Ratto 2013).

\section{Análisis zooarqueológico}

La muestra está compuesta por 109 especímenes óseos. Se registraron catorce (14) taxones correspondientes a Mamíferos, Aves y Bivalvos (Tabla 4). En el conjunto predominan los elementos óseos de mamíferos indeterminados ( $\mathrm{n}=25$; $22,94 \%$ ), de Lama guanicoe ( $\mathrm{n}=16 ; 14,68 \%$ ) y mamíferos grandes ( $\mathrm{n}=14 ; 12,84 \%)$. Entre los elementos óseos de esta especie, predominan los del autopodio (metapodios, astrágalos y falanges), vértebras torácicas, costillas y fragmentos de huesos largos (femúr y tibia). Los elementos de mamíferos grandes, en su mayoría son fragmentos de diáfisis de huesos largos. Es probable que correspondan también a Lama guanicoe, pero carecen de rasgos diagnósticos que permitan una identificación taxonómica más precisa. En menor medida se registraron restos de mamíferos medianos $(\mathrm{n}=12 ; 11,01 \%)$, aves indeterminadas ( $\mathrm{n}=7 ; 6,42 \%)$ y Ozotoceros bezoarticus $(\mathrm{n}=4 ; 3,67 \%)$. Este último está representado por elementos del autopodio (distal de metapodio, astrágalo y falanges).

\begin{tabular}{|l|l|l|l|}
\hline Taxón & NISP & NISP $\%$ & MNI \\
\hline Bivalvia indet. & 4 & 3,67 & 1 \\
\hline Aves indet. & 7 & 6,42 & 2 \\
\hline Mammalia indet. & 25 & 22,94 & - \\
\hline Mammalia indet. grande & 14 & 12,84 & - \\
\hline $\begin{array}{l}\text { Mammalia indet. } \\
\text { mediano }\end{array}$ & 12 & 11,01 & - \\
\hline Bos taurus & 1 & 0,92 & 1 \\
\hline Ovis aries & 5 & 4,59 & 1 \\
\hline Lama guanicoe & 16 & 14,68 & 2 \\
\hline Ozotoceros bezoarticus & 4 & 3,67 & 1 \\
\hline Cingulata Euphractinae & 6 & 5,50 & - \\
\hline Chaetophractus villosus & 5 & 4,59 & 1 \\
\hline Zaedyus pichiy & 4 & 3,67 & 1 \\
\hline Rodentia indet. & 4 & 3,67 & 1 \\
\hline Ctenomys sp. & 2 & 1,83 & 1 \\
\hline NISP Total & $\mathbf{1 0 9}$ & & \\
\hline
\end{tabular}

Tabla 4. Representación taxonómica del conjunto zooarqueológico de Laguna La Tigra 
La familia de los Dasipódidos se encuentra representada por placas móviles correspondiente a Chaetohractus villosus ( $\mathrm{n}=5 ; 4,59 \%)$ y Zaedyus pichiy ( $\mathrm{n}=4 ; 3,67$ $\%$ ) e indeterminados $(n=6 ; 5,50 \%)$. Entre los especímenes de Roedores $(n=6 ; 5,50$ $\%$ ), fueron identificadas dos hemimandíbulas completas de Ctenomys sp. Aunque minoritarios, fueron recuperados cuatro fragmentos pequeños de valva $y$ especímenes de fauna europea: Ovis aries $(\mathrm{n}=5 ; 4,59 \%)$ y Bos taurus $(\mathrm{n}=1 ; 0,92 \%)$. $\mathrm{Al}$ registro se suman y diecisiete (17) fragmentos de cáscaras de huevo asignadas a Rhea americana.

\begin{tabular}{|l|l|}
\hline Variable tafonómica & NISP\% \\
\hline Huellas de corte & - \\
\hline Fracturas antrópicas & $12,84 \%$ \\
\hline Alteración térmica & $18,34 \%$ \\
\hline Pisoteo & - \\
\hline Carnívoros & $1,83 \%$ \\
\hline Roedores & $7,33 \%$ \\
\hline Raíces & $24,77 \%$ \\
\hline Manganeso & $7,33 \%$ \\
\hline Sales & $41,28 \%$ \\
\hline Carbonato de calcio & $40,36 \%$ \\
\hline
\end{tabular}

Tabla 5. Frecuencia de variables tafonómicas identificadas.

A nivel tafonómico la variable natural que predomina en el conjunto, es la depositación de sales de sulfato $(41,28 \% ; n=45)$ y el carbonato de calcio $(40,36 \% ; n=$ 44, Tabla 5). La acción de raíces se presenta en el 24,77 \% ( $\mathrm{n}=27)$ de los especímenes, las marcas de roedores en el 7,33 \% $(n=8)$ de ellos y las de carnívoros solo en el 1,83 \% $(n=2)$ de los casos. Estas variables han sido identificadas principalmente en fragmentos de diáfisis de huesos largos. En cuanto al perfil de meteorización, la mayoría de los elementos óseos presentan estadios bajos, entre 1 y 2 (Tabla 6). Considerando las modificaciones de origen antrópico, a nivel macroscópico y con bajos aumentos no fueron identificadas, hasta el momento, huellas de corte. Sin embargo, se debe profundizar el análisis para descartar su presencia. El 12,84 \% (n = 14) de los elementos presenta fracturas antrópicas. Entre ellas, los tipos helicoidal y longitudinal son las más representadas. Con respecto a la termoalteración, el 18,34 \% ( $n=20)$ de los óseos se encuentra quemado. Entre ellos fragmentos de diáfisis de huesos largos de mamíferos grandes, cuerpos vertebrales y un fragmento de mandíbula de Lama guanicoe, placas de dasipódidos y cáscaras de huevo de ñandú. 


\begin{tabular}{|l|l|l|l|l|l|l|}
\hline & \multicolumn{7}{|c|}{ Meteorización } \\
\hline Taxón & Estadio 1 & Estadio 2 & Estadio 3 & Estadio 4 & Estadio 5 & Total \\
\hline Bivalvia indet. & 4 & - & - & - & - & 4 \\
\hline Aves indet. & 3 & 3 & 1 & - & - & 7 \\
\hline Mammalia indet. & 12 & - & 2 & 1 & 10 & 25 \\
\hline Mammalia indet. grande & 2 & 1 & 3 & 3 & 5 & 14 \\
\hline Mammalia indet. mediano & 3 & 2 & 2 & 5 & - & 12 \\
\hline Bos taurus & - & - & 1 & - & - & 1 \\
\hline Ovis aries & 5 & - & - & - & - & 5 \\
\hline Lama guanicoe & 4 & 6 & 3 & 3 & - & 16 \\
\hline Ozotoceros bezoarticus & 1 & 1 & 1 & 1 & - & 4 \\
\hline Cingulata Euphractinae & 3 & - & 1 & 2 & - & 6 \\
\hline Chaetophractus villosus & 5 & - & - & - & - & 5 \\
\hline Zaedyus pichiy & 4 & - & - & - & - & 4 \\
\hline Rodentia indet. & 4 & - & - & - & - & 4 \\
\hline Ctenomys sp. & 2 & - & - & - & - & 2 \\
\hline Total & 52 & 13 & 14 & 15 & 15 & $\mathbf{1 0 9}$ \\
\hline
\end{tabular}

Tabla 6. Perfil de meteorización del conjunto zooarqueológico.

\section{Otras Evidencias}

La cuenta de vidrio recuperada, presenta forma de torus con bordes redondeados. Se encuentra entera, tiene un peso de 0,24 g. y es de color azul opaco. Respecto a su diseño, es similar a las denominadas venecianas (Smith y Good 1982; Hajduk 1991). Presenta pequeñas vesículas circulares en la superficie externa donde se han depositado y formado cristales de sal y sulfatos (Figura 9, a). A pesar de esto, su estado de conservación general es bueno.

A partir de las observaciones macroscópicas y comparándola con fotografías de cuentas halladas en áreas vecinas (Flensborg 2017; Flensborg y Wagner 2015), se estima que fue confeccionada utilizando la técnica de globo de vidrio estirado en tubo (Kidd y Kidd 1983). Hajduk (1987) señala que esta técnica fue la más utilizada en Europa durante la época colonial gracias a su sencillez y posibilidad de producción a gran escala. Esto sería una de las razones por lo cual, este tipo de cuentas fueron las más exportadas desde Europa a las colonias y por ende, las más representadas en los registros arqueológicos.

Se recuperó además, un fragmento de borde de olla de fundición confeccionada en hierro gris (Figura 9, b). Sus dimensiones son de $16 \mathrm{~mm}$ de largo, 23,4 $\mathrm{mm}$ de ancho y 6 $\mathrm{mm}$ de espesor. Su peso es de 16,3 g. Se observan pequeñas cavidades porosas en ambas caras de la pieza las cuales pueden deberse al proceso de manufactura (Callister y Rethwisch 2016). La pieza se encuentra en buen estado de conservación, aunque presenta leves marcas ferrosas de oxidación y acumulación de sales en los poros. 


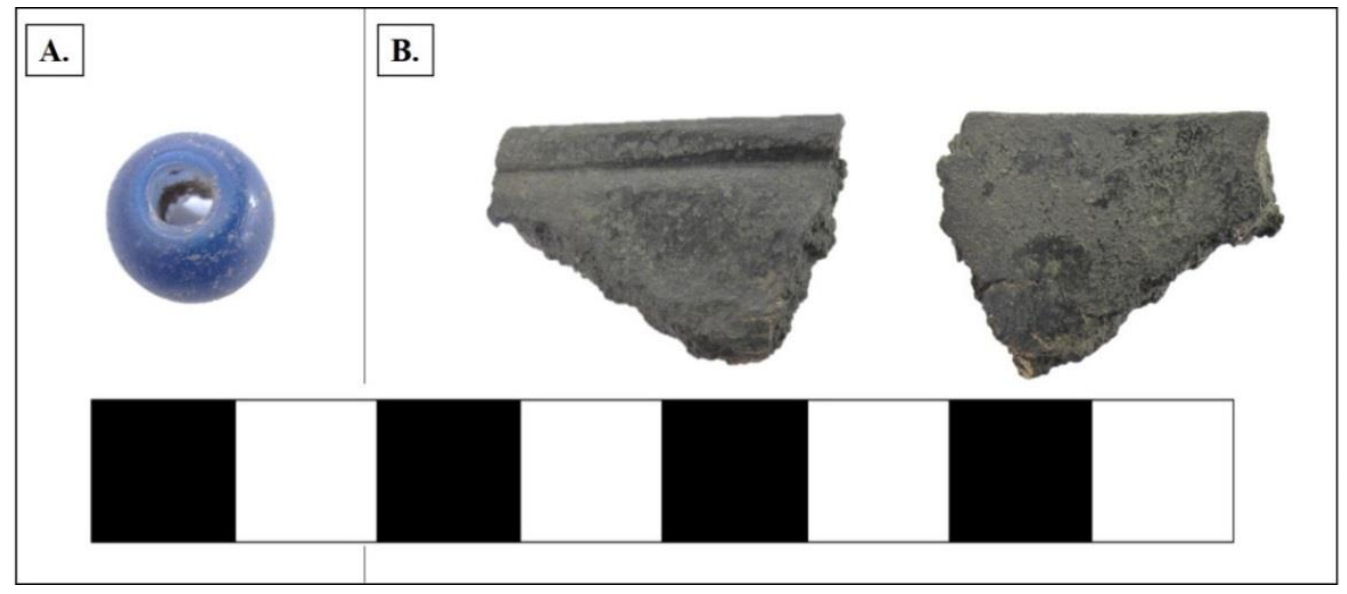

Figura 9. a) Cuenta de vidrio; b) Fragmento de olla de hierro fundido.

\section{Discusión}

Los entornos lagunares actuaron en el pasado como importantes concentradores de poblaciones humanas a lo largo del tiempo (Barrientos et al. 1997; Martínez 1999; Mazzia 2013; Politis y Madrid 1999). La dependencia central con estos ambientes, ha sido principalmente el suministro de agua y/o la explotación de sus recursos inmediatos (Prates y Bonomo 2017).

El agua de La Tigra es salobre, provocando que no sea apta para el consumo humano. Sin embargo, es un ecosistema donde se encuentran de manera localizada una variedad de recursos animales y vegetales adaptados al entorno. Es probable que por ello, este ambiente haya actuado, por lo menos, durante el Holoceno Tardío como un atractor para las poblaciones del pasado, que incluyeron este paraje dentro de sus circuitos de movilidad. Quizá esta laguna fue escogida por algún recurso en particular y el agua para beber fue transportada hasta aquí en contenedores cerámicos u otros; o posiblemente obtenida de manantiales o surgentes cercanos, situación observada en otras lagunas de la microrregión (Berón et al. 2002-2004).

Las distintas materialidades analizadas, permiten discutir y proponer ciertas interpretaciones sobre las actividades desarrolladas en el sitio, las estrategias de aprovisionamiento de recursos líticos implementadas por quienes transitaron este espacio, cuestiones relacionadas con la subsistencia, intercambio y circulación de bienes con diferentes grupos sociales de la Región Pampeana. Con respecto al conjunto lítico analizado, la frecuencia elevada de desechos, el predomino de lascas internas, tamaños relativos pequeños y muy pequeños, núcleos agotados y bajas proporciones de corteza, indicarían un aprovechamiento intensivo de las materias primas presentes en el registro arqueológico. Considerando que en la microrregión de valles transversales no hay fuentes de rocas aptas para la talla (Berón 2004, 2006; Berón et al. 2015; Carrera Aizpitarte 2014), las características morfológicas del conjunto, son las esperadas para sitios ubicados lejos de las fuentes de aprovisionamiento (Civalero y Franco 2003; Franco 1994, 2002, 2004 a, 2004 b). 
Las sílices y el chert son las materias primas más representadas entre las clases tipológicas analizadas (desechos, instrumentos y núcleos). Estas dos rocas permiten relacionar el registro arqueológico de La Tigra con el oeste y sur pampeano. Particularmente con el Manto Tehuelche, un conglomerado compuesto por rodados de diferentes litologías, entre las que predominan el basalto y las rocas silíceas (Berón 2004; Berón et al. 1995; Calmels et al. 1996; Carrera y Berón 2020) y con Meseta del Fresco, un extenso afloramiento de chert silíceo ubicado en el sudoeste de la provincia de La Pampa, a una distancia de $313 \mathrm{~km}$ del sitio (Berón 2006; Berón y Curtoni 2002; Carrera y Berón 2020; Curtoni et al. 2004).

En basalto se recuperaron desechos, un cuchillo de filo largo lateral y no se hallaron núcleos. La fuente principal de aprovisionamiento de esta materia prima es, al igual que la sílice, el Mano Tehuelche. Esto es interesante para pensar la representación diferencial entre ambas materias primas, ya que la sílice es la roca más representada del conjunto. Carrera y Berón (2020) proponen que las rocas del Manto Tehuelche fueron utilizadas de forma diferente a lo largo del tiempo en la subregión de Pampa Occidental. Los autores señalan que, durante los momentos más tempranos, el basalto fue la roca más explotada en los sitios y que su frecuencia en el registro arqueológico disminuye durante el Holoceno Tardío. En forma inversa, a lo largo de este periodo se registra un aumento constante en el empleo de la sílice. Proponen que esto pudo deberse a que a medida que se hacía efectiva la ocupación del espacio, los grupos humanos mejoraron e incrementaron su conocimiento acerca de los recursos líticos disponibles en el entorno, pudiendo reconocer y seleccionar aquellos de mejor calidad para la confección de sus herramientas. Esta tendencia podría explicar la baja frecuencia que presenta el basalto en todas las áreas donde predominan los sitios tardíos (Carrera y Berón 2020).

Particularmente, en el caso de La Tigra, si consideramos que la fuente de ambas materias primas es el Manto Tehuelche, su presencia diferencial en el registro, desestima una explicación relacionada con los costos de adquisición o disponibilidad, pues serían los mismos. Quizá estas rocas pudieron ser adquiridas a través de redes de intercambio con grupos asentados al oeste y sur de los valles. En el caso de que el aprovisionamiento hubiera sido directo, habría estado orientado principalmente a la selección de las rocas silíceas. Con respecto a las estrategias de aprovisionamiento del chert, todas las secuencias de producción lítica se encuentran representadas en el conjunto, lo que permitiría proponer un aprovisionamiento de forma directa a pesar de las distancias.

La presencia de calcedonia y cuarcita de grano fino indica a su vez, una relación hacia el este, con fuentes ubicadas en Pampa Oriental. Principalmente con los sistemas serranos de Tandilia y Ventania (Bayón et al. 1999; Flegenheimer et al. 1996; Flegenheimer et al. 1999; entre otros). Esto puede deberse principalmente a la posición privilegiada de los valles transversales como corredores de transitabilidad entre ambas 
subregiones, facilitando el intercambio y circulación de objetos, personas e ideas entre los grupos humanos que habitaron la macroregión (Berón 2004; Berón et al. 2002-2004; Berón et al. 2015; Carrera Aizpitarte 2014).

La baja proporción de núcleos de cuarcita y calcedonia, contrasta con la cantidad de desechos e instrumentos recuperados. Podría pensarse que ambas rocas ingresaron al sitio como preformas o instrumentos y que solo fueron realizadas tareas de reactivación y mantenimiento en el lugar. Otra posibilidad es que los núcleos no fueron descartados in situ. Estos datos se corresponden a la tendencia propuesta por otros autores que han trabajado diferentes sitios de la microrregión (Berón 1999, 2004; Berón et al. 2015; Carrera Aizpitarte 2013; Carrera Aizpitarte et al. 2009; Curtoni 2004).

Entre las materias primas minoritarias sobresale una variedad de sílice, denominado "sílice en plaqueta" (Berón et al. 2015; Carrera Aizpitarte 2014) o "sílice sedimentario" (Santos Valero y Armentano 2017) de cuya fuente no se tiene aún información precisa. Este tipo de sílice integra en forma de desechos e instrumentos los conjuntos líticos de diferentes sitios del área de Valles Transversales y también de Bajos sin Salida. Es probable que la fuente se encuentre en ésta última área de estudio, dado que entre los conjuntos líticos recuperados allí su representación aumenta notablemente. Santos Valero y Armentano (2017) también lo mencionan para el área del curso inferior del rio Colorado. En el conjunto de la Tigra se encuentra representada por muy pocos desechos y tres instrumentos. Al igual que en el caso de la cuarcita y la calcedonia, es probable que esta materia prima haya ingresado como preformas o instrumentos terminados.

Es importante destacar la presencia de obsidiana en este sitio, pues es el único caso identificado hasta el momento en Valles Transversales. La frecuencia de obsidiana en los contextos arqueológicos de La Pampa es baja, generalmente representada por desechos y pequeños instrumentos. Esto se debe a que es una materia prima con una disponibilidad regional limitada. En los últimos años, el Equipo de Pampa Occidental ha enfatizado los estudios de procedencia de esta materia prima, lo que ha permitido estudiar su uso y circulación de manera diacrónica y en una escala espacial amplia. En el caso de La Tigra, la obsidiana recuperada proviene de la subfuente Arroyo Paramillos, ubicada en la provincia de Mendoza (Berón et al. 2019; Cortegoso et al. 2012; Durán et al. 2004; de Francesco et al. 2018). Al tratarse de una subfuente asociada a la fuente de Laguna del Diamante (Salgán et al. 2015) y al propio sistema hidrológico del río Diamante cuya desembocadura se da en el río Salado, no se descarta la posibilidad de que pequeños rodados de obsidiana hayan viajado río abajo, desembocando finalmente en el Colorado. En este caso se podría pensar en un aprovisionamiento directo en alguna de las costas de estos ríos. Otra opción sería, que sea una materia prima obtenida a través de extensas redes de intercambio a larga distancia que se manifestaron durante el Holoceno Tardío y se expandieron a lo largo del Corredor Bioceánico Norpatagónico, como lo atestigua el registro arqueológico de los diferentes sitios de la subregión (Berón 2007a, 2007b; Berón et al. 2020). 
Con respecto a los instrumentos, el índice de fractura es elevado. Entre los enteros, principalmente raspadores, se observan evidencias de reactivación y filos embotados. Estas características podrían indicar que fueron descartados in situ al final de su vida útil (Guráieb 2004; Morrow 1997). A nivel general, no se observa una selección de materias primas para la confección de un tipo de instrumento en particular, con la excepción del granito. Es la única materia prima que fue exclusivamente utilizada para confeccionar artefactos modificados por picado pulido que posiblemente correspondan a elementos de molienda. Si bien estas conclusiones se encuentran sesgadas por la naturaleza superficial de la muestra y la probable redepositación que sufrieron los materiales, los datos indicarían que en este sitio fueron realizadas actividades de talla asociadas con las últimas etapas del sistema de producción lítica. Principalmente la confección y mantenimiento de instrumentos.

Sobre la cerámica, a pesar de que el conjunto se encuentra fragmentado, se han podido establecer ciertas tendencias. A nivel regional, la cerámica recuperada en La Tigra, pudo ser comparada con los grupos cerámicos definidos para la microrregión de la Cuenca media del río Colorado (sitio 1 de Casa de Piedra) y la microrregión de la Cuenca del Chadileuvú-Curacó (Localidad arqueológica Tapera Moreira). Esto indicaría una continuidad en la microrregión de los valles, en la elección de los recursos técnicos utilizados en el oeste pampeano. Además, se recuperó un tiesto decorado por incisión, técnica ya registrada en otros sitios de la provincia (Berón 2004).

La adopción de la tecnología cerámica permite un mayor aprovechamiento de los recursos a través del hervido o guisado de carne, vegetales y/o para la posible obtención de grasa (Berón 2000, 2004; Borges Vaz 2019). Esta tecnología facilita además el transporte y almacenamiento de agua en lugares carentes de agua potable (Prates y Bonomo 2015). En el sitio, no hay evidencia de elaboración in situ de cerámica, lo que indicaría que los contendedores fueron manufacturados en otro lugar y utilizados en la laguna. A futuro se espera realizar análisis de ácidos grasos en tiestos seleccionados, para ampliar las hipótesis referentes a los usos posibles de los contenedores.

En líneas generales, la diversidad y composición taxonómica del conjunto faunístico recuperado, es similar al de otros sitios de la microrregión (Berón et al. 2015). Con respecto a las evidencias de procesamiento antrópico, las fracturas intencionales de tipo helicoidal y longitudinal fueron registradas en el conjunto, principalmente en huesos largos de guanaco (Lama guanicoe) y venado de las pampas (Ozotoceros bezoarticus), a partir de las cuales podemos interpretar el posible consumo de médula de ambas especies. Llama la atención que no fueron detectadas hasta el momento huellas de corte. Esta situación puede deberse principalmente al tamaño de la muestra. Por otro lado, Day Pilaría (2019) ha propuesto una serie de escenarios posibles que pueden dar cuenta de la escasa presencia de huellas de corte en un conjunto arqueofaunístico. La autora propone que un aspecto a considerar es el donde se realiza el procesado de los animales. Por ejemplo en el área de captura se realizarían las tareas de trozamiento primario, provocando que la posibilidad de hallar marcas de corte en 
sitios caracterizados como campamentos residenciales, bajara notablemente. Otra posibilidad, es que los agentes tafonómicos naturales enmascaren las huellas de corte y otras marcas (Day Pilaría 2019). En el caso de los elementos óseos recuperados en la Tigra presentan buena integridad, sin embargo, la mayoría se encuentran mineralizados, producto de la incorporación de los minerales propios del agua de la laguna. En baja proporción, también algunos especímenes presentan pérdida de la capa ósea cortical, otro factor que puede dificultar la detección de huellas de corte. Otra modificación de posible origen antrópico es la termoalteración. Han sido identificados diferentes especímenes de guanaco quemados y carbonizados, así como elementos de fauna menor. Sobre esto último, se debe aclarar que si bien en ocasiones los huesos quemados son producto de la cocción, del uso como combustible o simplemente por cercanía al fuego (De Nigris 2004), puede deberse también a causas naturales (Yravedra Sainz de los Terreros 2013).

Se destaca la presencia de venado de las pampas en la laguna, pues es un indicador temporo-espacial de su rango de distribución natural, alterado $\mathrm{y}$ fragmentado a fines del siglo XIX y principios del XX por la utilización de las tierras en tareas agropecuarias, a la que se sumó una fuerte presión de caza (Berón et al. 2015; Day Pilaría et al. 2013). La presencia de elementos óseos correspondientes a oveja y vaca, posiblemente se deba a la incorporación de estos territorios para actividades ganaderas a comienzos del siglo XX hasta la actualidad (Pizarro 2003). Finalmente, los taxones de Rodentia y Aves indeterminadas, no presentan claras evidencias de consumo, por lo que se propone que su presencia en el sitio se deba a causas naturales.

Para momentos prehispánicos, las evidencias culturales permiten caracterizar a este sitio, como una base residencial en la que se llevaron a cabo actividades domésticas, probablemente con ocupaciones breves, pero recurrentes. Al fechado radiocarbónico de $590 \pm 20$ años AP (UGAMS 21347; Berón et al. 2015), se suma la presencia de una cuenta vítrea azul y un fragmento de olla de fundición que poseen cronologías estimadas para momentos post-hispánicos. Con respecto a la integridad del conjunto superficial analizado, este parece constituir un verdadero palimpsesto (sensu Bailey 2007). Sin embargo, las diferentes materialidades recuperadas, sumadas al fechado obtenido, permiten interpretar a este ambiente lagunar, como un espacio con diversas historias ocupacionales desde por lo menos ca. 600 años AP hasta tiempos históricos.

Las cuentas de vidrio recuperadas en diferentes contextos arqueológicos americanos han sido consideradas evidencias de la expansión colonial y la circulación de bienes europeos, especialmente entre los siglos XV y XVIII (Tapia y Pineau 2011). En Argentina se las registra en aproximadamente 50 sitios, la mayoría de ellos aborígenes asociados a contextos funerarios y domésticos (Flensborg y Wagner 2015; Oliva y Lisboa 2009; Tapia y Pineau 2011). También forman parte del registro arqueológico de sitios vinculados a ocupaciones hispano criollas, como es el caso de los asentamientos misionales y militares. En la provincia de La Pampa este tipo de materialidad ha sido 
registrada en el noroeste, en los sitios Chicalco (Gradín 1975) y Médano La Mamita (Aguerre 2002) y en el área de valles Transversales, particularmente en el sitio La Motta (Sanguinetti de Bórmida 1970) y en Naicó (Pera 2019). La mayoría de los casos pampeanos corresponden a contextos domésticos, exceptuando las cuentas de Naicó recuperadas en un contexto mortuorio. Estos sitios se ubican cronológicamente en el periodo hispano-indígena. La cuenta hallada en La Tigra, constituye un nuevo antecedente para el área de estudio y para las regiones vecinas.

La recurrencia de las cuentas venecianas en diferentes sectores del país, asociados a distintos contextos arqueológicos da cuenta del carácter altamente significativo y su rol primario en el intercambio entre colonizadores y poblaciones aborígenes (Tapia y Pineau 2011). Sin embargo, Flensborg y Wagner (2015) señalan que más allá de la interacción directa producto de la comunicación y los contactos fluidos que ambos actores sociales tenían en diferentes emplazamientos geográficos de Pampa-Patagonia, no se descartan otras posibilidades de obtención, como el intercambio de bienes entre los propios nativos (Berón 2007a; Gómez Otero 2007; Mazzanti 2007; Nacuzzi 1998).

Similar es el caso de las ollas de fundición, pues constituyen al igual que las cuentas venecianas un indicador cronológico del mismo lapso temporal. Durante el siglo XVI en Europa, se registra un cambio de producción al reemplazar las ollas de bronce por las de fundición por tratarse una técnica y un material más económico. A partir del siglo XVIII comienzan a ingresar por el puerto de Buenos Aires aumentando de manera exponencial su importación para no detenerse hasta el siglo XX (Landa 2010). Se propone a futuro realizar un análisis metalográfico sobre el fragmento hallado en el sitio, para determinar si su procedimiento de manufactura fue a través del método de moldeo u otro, y acotar así, el rango cronológico de producción (Callister et al. 2016).

La cuenta vítrea y el fragmento de olla hallados en La Tigra, son evidencia de la incorporación por parte de los grupos indígenas que habitaron el área, de objetos europeos en su vida cotidiana. Estos pudieron tener diferentes funciones, ya sea como bienes de intercambio, adornos personales, como marcadores de prestigio (Blair et al. 2009; Smith y Good 1982) o en el caso de las ollas, como bienes utilitarios. La presencia de estas materialidades en este ambiente lagunar, conforman nuevas evidencias que indican la importancia que tuvieron estos paisajes en tiempos históricos como puntos claves o nodos de articulación en los caminos indígenas que unían territorios muy distantes y regionalmente heterogéneos como la costa Atlántica y los pasos cordilleranos que conducían a Chile. Los mismos adquirieron un rol protagónico con posterioridad a la Conquista Española, debido a la necesidad de transportar grandes cantidades de ganado para su comercialización. En este contexto, las geoformas de los valles habrían favorecido la comunicación actuando como corredores de interacción entre los diferentes grupos sociales que habitaron y participaron en esta red intercambio desde por lo menos el siglo XII, que crecen paulatinamente a partir del siglo XVIII (Berón 1999, 2004; Berón et al. 2002-2004). 


\section{Conclusión}

A lo largo del Holoceno diferentes lagunas pampeanas han sido visitadas por grupos de cazadores-recolectores. La reutilización de estos espacios ha sido considerada en líneas generales, producto de eventos separados en el tiempo, mostrando cierta recurrencia en la localización de campamentos residenciales en márgenes de cuerpos lagunares (Aldazábal et al. 2004; Martínez 1999; Mazzia 2013; Mendonça et al. 2013; Messineo et al. 2018; Politis y Madrid 1999, 2001). La presencia de restos humanos en estos mismos espacios también implica una decisión social, ya que involucra mínimamente la elección de un lugar para enterrar a un miembro del grupo. Mazzia (2013) señala que no es el ambiente lagunar en sí mismo el que determina cómo van a aprovechar ese espacio las personas que se acerquen a sus orillas. En cambio, es en el continuo movimiento, en los recorridos que realizaban durante las distintas estaciones los cazadores recolectores, que estos lugares cobraron sentido. Indudablemente, la presencia de agua, aunque salobre debe haber tenido un rol fundamental para estos grupos sociales que habitaron esta área durante los últimos seis siglos.

Las investigaciones llevadas a cabo en la subregión de Pampa Occidental han posibilitado disponer actualmente, de un corpus de información que permite ir más allá de la escala del sitio y observar las particularidades del conjunto artefactual de La Tigra en un contexto espacial y temporal más amplio (Berón 2004, 2006, 2015; Berón et al. 2007, 2015, 2019, 2020; Carrera Aizpitarte 2014, Velardez 2005, 2018). Los resultados expuestos en este trabajo brindan nueva información sobre las ocupaciones humanas en la microrregión de Valles Transversales durante el Holoceno Tardío final.

Agradecimientos: En primer lugar, a mi Directora la Dra. Mónica Berón por su confianza, enseñanzas y el impulso necesario para escribir este trabajo. También quiero agradecer a Manuel Carrera Aizpitarte, Eliana Lucero, Ailín Guillermo, Erika Borges Vaz, Sabrina Labrone y María de la Paz Blanche, por sus sugerencias y paciencia. A la gente de Guatraché y a la Secretaria de Cultura de La Pampa. Este trabajo se enmarca dentro de un Proyecto de Arqueología Regional, dirigido por la Dra. Berón en La Pampa financiado por diferentes instituciones UBACyT, PIP-CONICET y PICTANPCyT.

\section{Notas}

1Fragmento no plano de materia prima que se desprenden durante el proceso de talla, de tamaño diverso y que no presentan ningún atributo típico de lasca o lámina

\section{Bibliografía citada}

Aguerre, A.

2002 Cabras, soledades y médanos. La arqueología del oeste pampeano. Entre médanos y caldenes de la pampa seca (ed. por A. Aguerre y A. Tapia), pp. 17-74. Oficina de Publicaciones de la Facultad de Filosofía y Letras, Buenos Aires. 
Aldazábal, V., Weiler, N. y E. Eugenio

2004 Una perspectiva geoarqueológica para comprender la ocupación humana en la costa central de la provincia de Buenos Aires. Intersecciones en Antropología 5: 29-38.

Aschero, C.

1975 Ensayo para una clasificación morfológica de artefactos líticos aplicada a estudios tecnológicos comparativos. Informe al CONICET. Buenos Aires. Ms.

1983 Ensayo para una clasificación morfológica de artefactos líticos aplicada a estudios tecnológicos comparativos. Apéndice A-C. Revisión 1983. Cátedra de Ergología y Tecnología. Facultad de Filosofía y Letras. Universidad de Buenos Aires. Buenos Aires. Ms.

Aschero, C. y S. Hocsman

2004 Revisando cuestiones tipológicas en torno a la clasificación de artefactos bifaciales. Temas de Arqueología. Análisis Lítico (comp. por A. Acosta, D. Loponte y M. Ramos), pp. 7-25. Universidad de Luján, Luján.

Barrientos, G., Leipus, M. y F. Oliva

1997 Investigaciones arqueológicas en la laguna Los Chilenos (provincia de Buenos Aires). Arqueología de la Región Pampeana en la década de los '90 (ed. por M. Berón y G. Politis), pp. 115-125. Museo Municipal de Historia Natural de San Rafael e INCUAPA, San Rafael.

Bailey, G.

2007 Time perspectives, palimpsests and the archaeology of time. Journal of Anthropological Archaeology 26, 198-223.

Bayón, C., Flegenheimer, N., Valente, M. y A. Pupio

1999 Dime cómo eres y te diré de dónde vienes: La procedencia de rocas cuarcíticas en la región pampeana. Relaciones de la Sociedad Argentina de Antropología XXIV: 187-235.

Behrensmeyer, A. K.

1978 Taphonomic and ecological information from bone weathering. Paleobiology 4: 150-162.

Bellelli, C., Guráieb, A. y J. García

1985-1987 Propuesta para el análisis y procesamiento por computadora de desechos de talla lítica (DELCO- desechos líticos computarizados). Arqueología Contemporánea 2: 36-53.

Berón, M.

1984 Análisis tipológico-técnico de un muestreo de los materiales líticos provenientes de los niveles superiores de la excavación del sitio Casa de Piedra 1, 
Provincia de La Pampa (Tesis de Licenciatura inédita). Facultad de Filosofía y Letras. Universidad de Buenos Aires, Buenos Aires.

1996-1998 Nuevos rumbos, viejos caminos. Cuenca Inferior del Chadileuvú (37³3`a $38^{\circ} 11^{\prime}$ Lat. Sur). Primer trabajo de campo 1996. Palimpsesto 5: 106-118

1999 Contacto, intercambio, relaciones interétnicas e implicancias arqueológicas. Soplando en el viento... Actas de las Terceras Jornadas de Arqueología de la Patagonia, pp. 287-302. Universidad Nacional del Comahue e Instituto Nacional de Antropología y Pensamiento Latinoamericano, Bariloche.

2000 Implementación de diferentes vías de análisis para la contrastación de manufactura cerámica en grupos cazadores- recolectores pampeanos. En Contribución arqueológica No 5, Actas del XIV Congreso Nacional de Arqueología Chilena (pp, 311336). Museo Regional de Atacama.

2004 Dinámica poblacional y estrategias de subsistencia de poblaciones prehispánicas de la cuenca Atuel-Salado-Chadileuvú-Curacó, provincia de La Pampa (Tesis Doctoral inédita). Facultad de Filosofía y Letras, Universidad de Buenos Aires, Buenos Aires.

2006 Base regional de recursos minerales en el occidente pampeano. Procedencia y estrategias de aprovisionamiento. Relaciones de la Sociedad Argentina de Antropología XXXI: 47-88.

2007a Circulación de bienes como indicador de interacción entre las poblaciones de la Pampa Occidental y sus vecinos. Arqueología en las Pampas (ed. por C. Bayón, A. Pupio, M. I. González, N. Flegenheimer y M. Frére), pp. 345-364. Sociedad Argentina de Antropología, Buenos Aires.

2007b Integración de evidencias para evaluar dinámica y circulación de poblaciones en las fronteras del río Colorado. Actas de las VI Jornadas de arqueología de la Patagonia. Punta Arenas, Chile.

2013 La arqueología de la región occidental de la región pampeana. Trayectoria y reposicionamiento respecto a la arqueología nacional. Revista del Museo de La Plata, sección Antropología 13(87): 7-29.

2015 Chronological distribution and disturbance factors to evaluate population dynamics in Western Pampas, Argentina. Quaternary International 356: 74-88.

2018 (Comp.) El sitio Chenque. Un cementerio prehispánico en la Pampa occidental. Estilo de vida e interacciones culturales de cazadores-recolectores del Cono Sur americano. Sociedad Argentina de Antropología, Buenos Aires.

Berón, M. y M. Carrera Aizpitarte

2020 Explotación de recursos líticos en dos canteras prehispánicas de la Provincia de la Pampa (Argentina): Meseta del Fresco y Manto Tehuelche. Estudios Atacameños. En prensa.

Berón, M., Carrera Aizpitarte, M., y F. Páez

2015 Arqueología en el área de Valles Transversales (provincia de La Pampa, Argentina). Caracterización y tendencia de los conjuntos arqueológicos. Implicancias 
sociales en la construcción del paisaje. Relaciones de la Sociedad Argentina de Antropología XL(2): 549-587.

Berón, M., Carrera Aizpitarte, M. y F. Páez

2020 Social Trajectories of Hunter-gatherer Societies in Central Argentina: Exploration and Colonization of a Desert Landscape, La Pampa Province, Argentina. One World Archaeology. South American Contributions to World Archaeology. En prensa.

Berón, M., Cimino, A., Curtoni, R., y R. Golpe

2007 Investigaciones arqueológicas en el sistema de Valles Transversales (Pcia. de La Pampa). Libro de resúmenes del XVI Congreso Nacional de Arqueología Argentina. San Salvador de Jujuy, Argentina.

Berón, M. y R. Curtoni

2002 Propuestas metodológicas para la caracterización arqueológica de canteras y talleres de la Meseta del Fresco (La Pampa, Argentina). Del Mar a los Salitrales. Diez mil años de Historia Pampeana en el Umbral del Tercer Milenio (ed. por D. Mazzanti, M. Berón y F. Oliva), pp. 171-184. Laboratorio de Arqueología. Facultad de Humanidades. Universidad Nacional de Mar del Plata, Mar del Plata.

Berón, M., Curtoni, R., Montalvo, C., Visconti, G., y A. Pérez

2002-2004 Arqueología en la Laguna de Chillhué (Departamento de Guatraché, La Pampa, República Argentina). Contribución a la historia de la formación de los territorios. Arqueología 12: 135-171.

Berón, M., di Biase, A., Musaubach, G., y F. Páez

2017 Enclaves y espacios internodales en la dinámica de poblaciones en el wallmapu. Aportes desde la arqueología pampeana. Estudios Atacameños 56: 253-272.

Berón, M., Migale, L. y R. Curtoni

1995 Hacia la definición de una base regional de recursos líticos en el área de Curacó. Una cantera taller: Puesto Córdoba (La Pampa, Argentina). Relaciones de la Sociedad Argentina de Antropología XX: 111-128.

Berón, M., Paez, F., Carrera Aizpitarte, M, Giesso, M. y M. Glascock

2018 Procurement and circulation of obsidian in the province of La Pampa, Argentina, Journal of Lithic Studies 5(2). https:/ / doi.org/10.2218/jls.2993

Binford, L.

1981 Bones: Ancient Men and Modern Myths. Academic Press, New York

Blair, E., Pendletony, L.S.A. y P. Francis

2009 The beads of St. Catherines Island. Anthropological papers of The American Museum of Natural History 82. American Museum of Natural History, New York 
Bonomo, $\mathrm{M}$.

2004 Ocupaciones humanas en el litoral marítimo pampeano. Un enfoque arqueológico (Tesis Doctoral inédita). Facultad de Ciencias Naturales y Museo, Universidad Nacional de La Plata, La Plata.

Borges Vaz, E.

2019 Modos de hacer y representar: las practicas alfareras en el curso inferior del río Colorado, durante el Holoceno tardío (Tesis Doctoral inédita). Facultad de Ciencias Sociales, Universidad Nacional del Centro de la Provincia de Buenos Aires, Olavarría.

Borges Vaz, E., Martínez, G. y P. Madrid

2016 Análisis tecnomorfológicos y tendencias cronológicas del conjunto cerámico del sitio Loma Ruíz 1 (transición pampeano-patagónica oriental). Aportes para Pampa y Norpatagonia. Intersecciones en Antropología 17(3): 269-280.

Callister, W. D y D. G. Rethwisch

2016 Ciencia e ingeniería de materiales. Reverté, Barcelona.

Calmels, A. P.

1996 Bosquejo Geomorfológico de la Provincia de La Pampa. UNLPam, Santa Rosa.

Calmels, A. P. y S. A. Casadío

2004 Compilación Geológica de la provincia de La Pampa. UNLPam, Santa Rosa.

Calmels, A., Aldacour, H., Fernández, E. y O. Carballo

1996 Las unidades litoestratigráficas de Anzoátegui, provincia de La Pampa. Actas de la Sexta Reunión Argentina de Sedimentología y Primer Simposio de Arcillas, pp. 97-104. Bahía Blanca.

Carrera Aizpitarte, M.

2014 Estudios de las estrategias de aprovisionamiento lítico en las áreas Curacó, Bajos sin Salida, Valles Transversales y Centro-este (provincia de La Pampa, Argentina) (Tesis Doctoral inédita). Facultad de Ciencias Sociales, Universidad Nacional del Centro de la Provincia de Buenos Aires, Olvarría.

Carrera Aizpitarte, M., Merlo, J. y R. Curtoni

2009 Investigaciones arqueológicas en el área centro-este de la provincia de La Pampa: El sitio Laguna de Paisani (Departamento de Toay). Arqueología en Las Pampas (ed. por C. Bayón, A. Pupio, M. I. González, N. Flegenheimer y M. Frére), pp. 491-510. Sociedad Argentina de Antopología, Buenos Aires.

Casanova, E., Knowles, T., Bayliss, A., Dunne, J., Barański, M., Denaire, A., Lefranc, P., di Lernia, S., Roffet-Salque, M., Smyth, J., Barclay, A., Gillard, T., Claben, E., Coles, B., Ilett, M., Jeunesse, C., Krueger, M., Marciniak, A., Minnitt, S., Rotunno, R., van de Velde, P., van Wijk, I., Cotton, J., Daykin, A. y P. Evershed 
2020 Accurate compound-specific 14C dating of archaeological pottery vessels. Nature.

Civalero, M. y N. Franco

2003 Early human occupations in Western Santa Cruz Province, Southernmost South America. Quaternary International 109-110: 77-86.

Cortegoso, V., Neme, G., Giesso, M., Durán, V. y A. Gil

2012 El uso de la obsidiana en el sur de Mendoza. Paleoecología humana en el sur de Mendoza (ed. por A. Gil y G. Neme), pp. 180-211. Sociedad Argentina de Antropología, Buenos Aires.

Curtoni, R.

1996 Experimentando con bipolares: indicadores e implicancias arqueológicas. Relaciones de la Sociedad Argentina de Antropología XXI: 187-214.

Curtoni, R., Barros, P. y M. Berón

2004 Meseta del Fresco: análisis de canteras y talleres. La Región Pampeana. Su pasado arqueológico (ed. por C. Gradin y F. Oliva), pp. 287-296. Laborde Editor, Rosario.

Day Pilaría, F.

2019 Pocos Cortes, ¿Buenos Procesadores? El Caso de los Conjuntos Arqueofaunísticos de los Sitos del Litoral del Río de La Plata. Comechingonia. Revista de Arqueología Vol. 23(2): 59-79.

Day Pilaría F., Merino, M. y R. Gambaro

2013 Explotación y consumo de cérvidos en el litoral fluvial bonaerense durante el Holoceno tardío final: análisis de los sitios San Clemente VI y Las Marías. Revista del Museo de La Plata, Sección Antropología 13(87): 153-166.

de Francesco, A.M., Barca, D., Bocci, M., Cortegoso, V., Barberena, R., Yebra, L. y V. Durán

2018 Provenance of obsdian artifacts from the Natural Protected Area Laguna del Diamante (Mendoza Province, Argentina) and Upper Maipo valley (Chile) by LAICPMS method. Quaternary International 468: 134-140.

De Nigris, M. E.

2004 El consumo en grupos cazadores recolectores. Un ejemplo zooarqueológico de Patagonia meridional. Sociedad Argentina de Antropología, Buenos Aires.

Durán, V., Giesso, M., Glascock, M., Neme, G., Gil, A. y L. Sanhueza

2004 Estudio de fuentes de aprovisionamiento y redes de distribución de obsidiana durante el Holoceno tardío en el sur de Mendoza (Argentina). Estudios Atacameños 28: $25-43$. 
Feely, A. y N. Ratto

2013 Cálculo del número mínimo de vasijas y recolección superficial: criterios metodológicos y análisis de casos del oeste Tinogasteño (Catamarca). Andes 24: 425-445.

Flegenheimer, N., Bayón, C. y M. I. González De Bonaveri

1995 Técnica simple, comportamientos complejos: la talla bipolar en la arqueología bonaerense. Relaciones de la Sociedad Argentina de Antropología XX: 81-110.

Flegenheimer, N., Kain, C., Zárate M. y A. Barna

1996 Aprovisionamiento de cuarcitas en Tandilia, las canteras del Arroyo Diamante. Arqueología 6: 117-141.

Flegenheimer, N., Zárate, M. y M. Valente

1999 El área de canteras Arroyo Diamante, Barker, Sierras de Tandil. Actas del XII Congreso Nacional de Arqueología Argentina (ed. por C. Diez Marín), pp. 134-148. Facultad de Ciencias Naturales y Museo, Universidad Nacional de La Plata, La Plata.

Flensborg, G.

2018 Análisis tecnomorfólogico de adornos, cuentas y otros ornamentos. Arqueología de cazadores-recolectores del curso inferior del río Colorado (provincia de Buenos Aires, Argentina). Aportes al conocimiento de las ocupaciones humanas Pampeano-Patagónicas (ed. por G. Martinez), pp. 230-254. Universidad Nacional del Centro de la Provincia de Buenos Aires, Facultad de Ciencias Sociales, Tandil.

Flensborg, G. y C. Wagner

2015 Cuentas vítreas asociadas a entierros humanos en el curso inferior del río Colorado (transición pampeano-patagónica oriental). Intersecciones en Antropología 16: 237-245.

Franco, N.

1994 Maximización en el aprovechamiento de recursos líticos. Un caso analizado en el Área Interserrana Bonaerense. Edición Especial de Arqueología Contemporánea 5: Arqueología de Cazadores Recolectores: Límites, Casos y Aperturas (comp. por J.L. Lanata y L. Borrero), pp. 75-88. Programa de Estudios Prehistóricos, Buenos Aires.

2002 Estrategias de utilización de recursos líticos en la cuenca superior del río Santa Cruz (Tesis Doctoral inédita). Facultad de Filosofía y Letras, Universidad de Buenos Aires, Buenos Aires.

2004a Rangos de acción, materias primas y núcleos preparados al sur de Lago Argentino. Contra Viento y Marea. Arqueología de la Patagonia (comp. por M. T. Civalero, P. Fernández y A. G. Guráieb), pp. 105-116. Instituto Nacional de Antropología y Pensamiento Latinoamericano y Sociedad Argentina de Antropología, Buenos Aires.

2004b La organización tecnológica y el uso de escalas espaciales amplias. El caso del sur y oeste de Lago Argentino. Temas de Arqueología, Análisis Lítico (comp. por A. Acosta, D. Loponte y M. Ramos), pp. 101-144. Universidad Nacional de Luján, Luján. 
Gradin, C.

1975 Contribución a la arqueología de La Pampa. (Arte Rupestre). Dirección Provincial de Cultura. Panzini Hnos. S.A.I.C., Santa Rosa.

Grayson, D.

1984 Quantitative Zooarchaeology: Topics in the Analysis of Archaeological Faunas. Academic Press, Orlando.

Gómez Otero, J.

2007 Dieta, uso del espacio y evolución en poblaciones cazadoras-recolectoras de la costa centro-septentrional de Patagonia durante el Holoceno medio y tardío (Tesis Doctoral inédita). Facultad de Filosofía y Letras, Universidad de Buenos Aires, Buenos Aires.

Guráieb, A. G.

2004 Selección de materias primas para la confección de raspadores en contexto de Cerro de Los Indios 1 (Lago Posadas, Santa Cruz, Argentina). Chungará (Arica) 36: 1528.

Hajduk, A.

1987 Cuentas vítreas de sección estrellada, provenientes de Rey Don Felipe, antigua fundación hispana de fines del siglo XVI (Patagonia austral chilena). Anales del Instituto de la Patagonia 17: 41-46.

1991 Las cuentas vítreas del sitio arqueológico Caepe Malal I (Departamento de Chos Malal, Neuquén) como indicadores temporales. Cuadernos de Investigación, Arqueología y Etnohistoria de la Patagonia Septentrional (ed. por M. T. Boschín), pp. 36-48. Instituto de Estudios Histórico Sociales (IEHS), Universidad Nacional del Centro de la Provincia de Buenos Aires, Olavarría.

Haynes, G.

1980 Evidence of carnivore gnawing on Pleistocene and recent mammalian bones. Paleobiology 6: 341-351.

INTA - Gobierno de La Pampa - UNLPam (1980). Inventario Integrado de los Recursos Naturales de la Provincia de La Pampa. Buenos Aires, 493 pp.

Johnson, E.

1985 Current developments in bone technology. Advances in Archaeological Method and Theory (ed. por M.B. Schiffer), pp. 157-235. Academic Press, New York.

Kidd, K. y M. Kidd

1983 A Classification System for Glass Beads for the Use of Field Archaeologist. Proceedings of 1982 glass trade bead conference (ed. por C. Hayes), pp. 219-255. III Research Record 16 Rochester Museum and Science Center, Nueva York. 
Kidd, M y E. Kenneth

2006 A Classification System for Glass Beads for the Use of Field Archaeologists. Disponible en: http:// parkscanadahistory.com/series/chs/1/chs1-2a.htm

Klein, R. G. y K. Cruz-Uribe

1984 The Analysis of Animal Bones from Arehaeological sites. The University of Chicago Press, Chicago.

Küppers, $\mathrm{H}$.

2002 Atlas de los colores. Barcelona Press, Blume.

Landa, C.

2010 Análisis de artefactos provenientes del Fortín Otamendi (1858-1869) Vinculados a las prácticas alimenticias. 3er. Encuentro de Jóvenes Investigadores en Ciencia y Tecnología de Materiales. Universidad Tecnológica Nacional, Delegación Regional de Concepción del Uruguay, Concepción del Uruguay.

Lyman, R. L.

1994 Vertebrate Taphonomy. Cambridge University Press, Cambridge.

Martínez, G.

1999 Tecnología, Subsistencia y Asentamiento en el Curso Medio del Río Quequén Grande: Un Enfoque Arqueológico (Tesis doctoral inédita), Facultad de Ciencias Naturales y Museo, UNLP, La Plata.

2008-2009 Arqueología del curso inferior del río Colorado: Estado actual del conocimiento e implicaciones para la dinámica poblacional de cazadores-recolectores pampeano-patagónicos. Cazadores-recolectores del Cono Sur. Revista de Arqueología 3: 71-92.

2017 (ed) Arqueología de cazadores-recolectores del curso inferior del río Colorado (provincia de Buenos Aires, Argentina). Aportes al conocimiento de las ocupaciones humanas PampeanoPatagónicas. Universidad Nacional del Centro de la Provincia de Buenos Aires, Facultad de Ciencias Sociales, Tandil.

Mazzia, N.

2014 Morar en las Lagunas: Lugares de Cazadores Recolectores en la Pampa Bonaerense (Argentina). Revista Chilena de Antropología, 53-78.

Mazzanti, D.

2007 Arqueología de las relaciones interétnicas posconquista en las Sierras de Tandilla (Tesis Doctoral inédita). Facultad de Filosofía y Letras, Universidad de Buenos Aires.

Medus, N., Hernández, R. y W. Cazenave

1982 Geografía de La Pampa. Editorial Extra, Santa Rosa. 
Mendonça, O., Aguerre, A., Arrieta, M. y L. Pera

2013 Investigaciones bioarqueológicas en la laguna Chadilauquen, Embajador Martini, departamento Realicó, Provincia de La Pampa. Segunda etapa. Revista del Museo de La Plata, Sección Antropología 13(87): 137-152.

Mengoni Goñalons, G.

1999 El aprovechamiento del guanaco en el interior de Patagonia Meridional: transporte y procesamiento en la localidad arqueológica de Cerro de los Indios 1 (Santa Cruz). Sociedad Argentina de Antropología.

2006-2010 Zooarqueología en la práctica: algunos temas metodológicos. Xama 19-23 83-113.

Mera, R., Mille, B., Munita, D., y V. Figueroa

2015 Cooper earrings in la Araucanía: earliest evidence of metal usage in southern Chile. Latin American Antiquity, 26(1), 106-119.

Mera, R. y D. Munita

2008 Informe ejecutivo salvataje sitio "Villa JMC-01-Labranza" (Provincia de Cautín, región de la Araucanía. 57 pp. Chile, Manuscrito entregado a CMN.

Messineo, P. G.; González., M. E., Álvarez, M. C. y N. Pal

2018 Las Ocupaciones Humanas en La Localidad Arqueológica Laguna de Los Pampas (Campo de Dunas del Centro Pampeano, Región Pampeana Argentina) Durante el Holoceno. Latin American Antiquity.

Morrow, J.

1997 End scrapers morphology and use-life: An approach for studying paleoindian lithic technology and mobility. Lithic Technology 22: 70-85.

Nacuzzi, L. R.

1998 Identidades impuestas. Tehuelches, aucas y pampas en el norte de Patagonia. Sociedad Argentina de Antropología, Buenos Aires.

Nami, $H$.

2000 Investigaciones actualísticas y piedra tallada. Actas del III Congreso Argentino de Americanistas, pp. 229- 270. Sociedad Argentina de Americanistas, Buenos Aires.

Oliva, F. y M. L. Lisboa

2009 Indicadores arqueológicos de cambio cultural en las comunidades indígenas pampeanas de los primeros momentos históricos (siglos XVI a XVIII). Región Pampeana, República Argentina. Arqueología Colonial Latinoamericana, Modelos de Estudio (ed. por J. G. Targa y P. F. García), pp. 255-267. BAR International Series 1988. Archaeopress, Oxford. 
Olsen, S. y P. Shipman

1988 Surface modification on bone: trampling versus butchery. Journal of Archaeological Science 15: 535-553.

Paulides, L.

2006 El núcleo de la cuestión: el análisis de los núcleos en los conjuntos líticos. El modo de hacer las cosas: artefactos y ecofactos en arqueología (ed. por C. Pérez de Micou), pp. 67-100. Universidad de Buenos Aires, Facultad de Filosofía y Letras, Buenos Aires.

Pera, L.

2019 Hallazgos arqueológicos en Naicó: El camino del consenso. Revista Rastrilladas 3: 79.

Pizarro, J.

2003 La evolución de la producción agropecuaria pampeana en la segunda mitad del siglo XX. Revista Interdisciplinaria de Estudios Agrarios 18: 63-125.

Politis, G. y P. Madrid

2001 Arqueología pampeana: estado actual y perspectivas. Historia Argentina Prehispánica (ed. por E. Berberián y A. Nielsen), pp. 737-813. Editorial Brujas, Córdoba.

Prates, Ly M. Bonomo

2017 Los ambientes acuáticos en arqueología. Arqueología 23(3): 11-33.

Ringuelet, $R$.

1961 Rasgos fundamentales de la Zoogeografía de la Argentina. Physis 22(63): 151-170.

Rodier, J.

2009 Análisis del agua. AMV Ediciones, Madrid.

Salgán, L., Garvey, R., Neme, G., Gil, A., Giesso, M., Glascock, M. y Durán

2015 Las Cargas: Characterization and Prehistoric Use of a Southern Andean Obsidian Source. Geoarcheology: An International Journal 30: 139-150.

Sanguinetti De Bórmida, A.

1970 La neolitización de las áreas marginales de la América del Sur. Relaciones V1: 9-23.

Santos Valero, F. y G. Armentano

2017 La tecnología lítica. Arqueología de cazadores-recolectores del curso inferior del río Colorado (provincia de Buenos Aires, Argentina). Aportes al conocimiento de las ocupaciones humanas Pampeano-Patagónicas (ed. por G. Martínez), pp. 121-145. Universidad Nacional del Centro de la Provincia de Buenos Aires, Facultad de Ciencias Sociales, Tandil. 
Shipman, P.

1981 Life History of a Fossil. Harvard University Press, Cambridge.

Smith, M. y M. Good

1982 Early sixteenth century glass beads in the Spanish colonial trade. Cottonlandia Musuem Publications, Greenwood.

Tapia, A. y V. Pineau

2011 Diversidad de las cuentas vítreas. Los hallazgos de la misión de Santiago del Baradero (Siglo XVII). Arqueología 17: 1-18.

Terraza, J.C., Cruz, C.E. y J. A. Sbrocco

1981 Geología de los valles de Utracán, Quehué y Chapacó, provincia de La Pampa. $8^{\circ}$ Congreso Geológico Argentino Actas 3: 183-192, San Luis

Valverde, F. y M. Martucci

2004 Estudio tecno-tipológico de las puntas de proyectil del sitio Cueva El Abra (provincia de Buenos Aires). Aproximaciones Contemporáneas a la Arqueología Pampeana. Perspectivas teóricas, metodológicas, analíticas y casos de estudio (ed. por G. Martínez, M. Gutiérrez, R. Curtoni, M. Berón y P. Madrid), pp. 419-434. Facultad de Ciencias Sociales, Universidad Nacional del Centro de la Provincia de Buenos Aires, Olavarría.

Velardez, S.

2005 Los artefactos líticos del sitio Chenque I (Parque Nacional Lihué Calel, provincia de La Pampa). Caracterización de un conjunto artefactual en el contexto de un área destinada al entierro de los muertos. (Tesis de Licenciatura inédita). Facultad de Filosofía y Letras, Universidad de Buenos Aires, Buenos Aires.

2018 Estrategias tecnológicas, secuencias de producción y distribución diferencial. El conjunto artefactual lítico del sitio Chenque I desde distintas perspectivas. El sitio Chenque. Un cementerio prehispánico en la Pampa occidental. Estilo de vida e interacciones culturales de cazadores-recolectores del Cono Sur americano (comp. por M. Berón), pp. 177-223. Sociedad Argentina de Antropología, Buenos Aires.

Yavedra Sainz de los Terreros, J.

2013 Tafonomía aplicada a zooarqueología. Universidad Nacional de Educación a Distancia, Madrid. 